PALABRAS CLAVE

Macroeconomía

Desarrollo económico

CEPAL

Análisis económico

Política económica

Política monetaria

Política fiscal

Balanza de pagos

Tipos de cambio

Diversificación de la producción

Innovaciones

Estrategias del desarrollo

América Latina
José Antonio Ocampo

Profesor y miembro del Comité sobre

pensamiento global de la Universidad

de Columbia y ex Secretario Ejecutivo

de la Comisión Económica para América

Latina y el Caribe (CEPAL)

- jao2128@columbia.edu
REVISTA CEPAL 104 - AGOSTO 2011

Ensayo basado en la Conferencia magistral realizada en la Comisión Económica para América Latina y el Caribe (CEPAL), en Santiago de Chile, el 12 de abril de 2011, en el marco de la Décima Cátedra Raúl Prebisch.

\section{Macroeconomía para el desarrollo: políticas anticíclicas y transformación productiva}

\author{
José Antonio Ocampo
}

$\mathrm{E}$

n este ensayo se argumenta que la clave de una acertada macroeconomía para el desarrollo es la combinación de buenas políticas anticíclicas con una estrategia activa de diversificación productiva, dos conceptos que tienen profundas raíces en el pensamiento de la CEPAL. La política anticíclica debe enfrentar los retos que implican los agudos ciclos de financiamiento externo y las acentuadas fluctuaciones de los precios de productos básicos. La política fiscal es fundamental, pero debe estar acompañada de una política monetaria y cambiaria igualmente anticíclica. A la luz de la experiencia del último decenio, ello parece posible con regímenes cambiarios intermedios en conjunto con políticas macroprudenciales, que incluyen regulaciones a los flujos de capital. A su vez, la estrategia de desarrollo productivo debe fomentar las actividades innovadoras que generan encadenamientos productivos. La innovación debe entenderse en un sentido amplio, pero su prueba decisiva es la capacidad de acumular capacidades tecnológicas. 


\section{I}

\section{Introducción}

La reciente crisis financiera internacional ha sido una prueba de fuego para el análisis macroeconómico, como lo fue en el pasado la crisis de los años treinta del siglo XX. $\mathrm{Ni}$ de la una ni de la otra salieron bien libradas las ideas económicas ortodoxas sobre autorregulación de los mercados que habían predominado en los años previos a la crisis. La de los años treinta fue, además, el origen de lo que hoy conocemos como el análisis macroeconómico, que nació bajo el liderazgo intelectual de John Maynard Keynes. Desafortunadamente, la macroeconomía no fue siempre fiel a su legado. La preocupación por los efectos inflacionarios que puede generar el activismo monetario $\mathrm{y}$ fiscal keynesiano fue el origen de las nuevas visiones ortodoxas, que resurgieron con el monetarismo de los decenios de 1950 y 1960. La crisis reciente ha hecho renacer con fuerza la vigencia de Keynes, en particular sus reflexiones sobre la inestabilidad que es inherente a los sistemas financieros y el papel dominante que desempeña la demanda agregada en la determinación del nivel de actividad económica y el empleo.

Para el mundo en desarrollo y para América Latina, las crisis también han sido gestoras de ideas y prácticas económicas. La de la década de 1930 representó el origen de las formas de pensamiento económico que luego se desarrollarían en la Comisión Económica para América Latina y el Caribe (CEPAL) bajo el liderazgo intelectual de Raúl Prebisch y darían lugar a una corriente de pensamiento que vino a denominarse el estructuralismo latinoamericano. En épocas más recientes, la repercusión de los pronunciados ciclos financieros internacionales experimentados por los países en desarrollo desde el decenio de 1970 del siglo XX, $\mathrm{y}$ las crisis financieras y de balanza de pagos que los han acompañado, han gestado nuevas ideas macroeconómicas de diverso signo. El relativo éxito que tuvo el mundo en desarrollo en lidiar con las turbulencias económicas mundiales de los últimos años puede ser un indicio de que finalmente hemos aprendido a manejarlas. Por ello es esencial saber interpretar correctamente cuáles son los factores que contribuyeron a este resultado.

$\square$ Las ideas aquí expresadas se han desarrollado en interacción con muchos colegas, a quienes agradezco enormemente. La literatura sobre estos temas es, además, extensa y — sin duda- no le hago entera justicia en este ensayo. Como síntesis de muchos trabajos del autor, se hace un uso extenso de ellos.
El análisis macroeconómico nació de la necesidad de entender la dinámica macroeconómica de corto plazo, pero también incorporó más tarde el análisis del crecimiento económico. Aquí las ideas esenciales surgieron en las décadas de 1940 y 1950 y se desarrollaron en los decenios siguientes. El concepto que vino a ocupar el centro de atención es el papel que cumple el cambio tecnológico como motor de crecimiento, aunque estrechamente ligado a la acumulación de capital físico y humano. Para los países en desarrollo, este análisis estuvo mezclado desde sus orígenes con tres conceptos adicionales: i) el papel de los excedentes de mano de obra y el dualismo en los mercados de trabajo al que dan lugar (que se vincula muy especialmente a las contribuciones del economista caribeño W. Arthur Lewis); ii) el de las restricciones de balanza de pagos, tanto en la dinámica de corto como de largo plazo, iii) y el papel central del proceso de industrialización como mecanismo de transmisión del progreso técnico. En este último caso, esa transmisión opera en parte a través de la inversión en maquinaria y equipo, pero un fenómeno más interesante son las economías de escala dinámicas que generan los procesos de aprendizaje característicos de la industrialización.

La CEPAL y el pensamiento económico estructuralista han estado, ayer como hoy, en el centro de estos debates. Raúl Prebisch, en cuyo honor se creó esta cátedra, fue por supuesto el gran pionero de estas ideas. Por eso, en la sección II se resumen algunas de las principales contribuciones de Prebisch y la CEPAL al análisis macroeconómico. Esta discusión es sucedida en la sección III por una mirada al principal determinante de los ciclos económicos en el mundo durante las últimas décadas - los ciclos financieros internacionales-, y lo que esto implica para un buen manejo anticíclico de la política macroeconómica. La relación entre crecimiento económico y estructura productiva, así como entre macroeconomía y desarrollo productivo son objeto de atención en la sección IV, y se resalta con respecto a esta última interacción el papel crítico del tipo de cambio. En estas dos secciones se alude, además, a la experiencia reciente de América Latina para comprobar en qué medida la región ha seguido las políticas apropiadas a la luz de estos conceptos. En la sección V se presentan las conclusiones. 


\section{II}

\section{La CEPAL y el análisis macroeconómico}

\section{Los aportes clásicos}

A riesgo de incurrir en alguna simplificación, se puede decir que las principales contribuciones de la CEPAL al pensamiento macroeconómico se focalizan en dos conceptos. El primero se refiere al papel crucial que cumple la balanza de pagos como determinante de los ciclos económicos de los países en desarrollo y, por ende, como centro de atención de las políticas anticíclicas. El segundo es la importancia del cambio en las estructuras productivas en el crecimiento económico a largo plazo, con la industrialización como su expresión más relevante. Ambas ideas tienen implicancias respecto de la acción del Estado y están, además, ligadas a una concepción del orden económico internacional como un sistema centro-periferia, donde los ciclos económicos y el progreso técnico se originan en el centro y se difunden a la periferia. A estas ideas pueden agregarse al menos dos más: la necesidad de mejorar los mecanismos de financiación y lo que se ha dado en denominar la teoría estructuralista de la inflación; sin embargo, por razones de espacio, solo serán objeto de atención marginal en este ensayo.

El primero de estos conceptos nació de la crisis mundial de la década de 1930. La vinculación entre choques externos y ciclos económicos era muy conocida en la región y en materia de política económica ella se había reflejado en la tendencia de un grupo importante de países a abandonar el patrón oro o el patrón plata por períodos más o menos prolongados, aunque siempre con la aspiración de retornar al patrón metálico y, por ende, obedecer sus "reglas de juego". La crisis del decenio de 1930 cambió radicalmente esta tendencia, porque destrozó los cimientos de la ortodoxia con el colapso definitivo del patrón oro en el propio centro. La teoría y práctica económicas experimentaron cambios fundamentales: la idea central, que captó el pensamiento keynesiano, es que la tarea fundamental de la política macroeconómica es moderar los ciclos económicos mediante políticas monetarias y fiscales activas.

La política macroeconómica anticíclica surgió también en América Latina como resultado a raíz de la misma crisis, pero las modalidades dominantes de intervención en el funcionamiento del mercado fueron distintas, como reflejo de los diferentes determinantes del ciclo económico en el centro y la periferia de la economía mundial. En efecto, mientras el eje del pensamiento keynesiano fue la estabilización de la demanda agregada mediante una política fiscal y monetaria activa, el predominio de los choques externos - tanto por intermedio de los precios de los productos básicos como de la cuenta de capitales- hizo que el foco de atención se desplazara en los países latinoamericanos hacia la balanza de pagos.

En el análisis macroeconómico tradicional se ha desarrollado el concepto de dominancia fiscal (fiscal dominance), o mejor de "predominio fiscal", para referirse a situaciones en que la política monetaria está dominada por lo que acontece con las finanzas públicas. Utilizando un término similar, se puede decir que el concepto cepalino es el de "predominio de la balanza de pagos" en la dinámica macroeconómica de corto plazo. Esto implica que la tarea macroeconómica fundamental de la política económica consiste en cómo moderar los choques de oferta agregada de origen externo, más que el manejo de la demanda agregada. Este último queda, por lo tanto, subordinado a los márgenes que la política económica es capaz de construir gracias a una conducción adecuada del ciclo de oferta de origen externo. Más aún, el problema fundamental en materia del comportamiento de la demanda agregada es que los ciclos externos tienden a producir efectos esencialmente procíclicos: por la vía del ingreso de los exportadores, de la disponibilidad y costo del financiamiento externo y de los efectos que ello tiene en las tasas de interés internas, con efectos algo más ambiguos en el tipo de cambio. Estos temas se abordarán más adelante.

No en vano, la intervención en la balanza de pagos se transformó en el principal foco del manejo macroeconómico en los países latinoamericanos, con el fin de manejar las perturbaciones externas tanto negativas como positivas. El aparato de intervención se tornó cada vez más complejo: con variantes nacionales, incluyó el control de cambios y de capitales; aranceles y control directo a las importaciones; impuestos a las exportaciones tradicionales e incentivos a las no tradicionales; tipos de cambio múltiples y, desde mediados del decenio de 1960, regímenes de devaluación gradual. Desde la década de 1970, los procesos de liberalización económica racionalizarían y desmontarían muchos de 
estos instrumentos de intervención, dejando descansar el manejo de la balanza de pagos sobre uno de ellos, el tipo de cambio, cuyos efectos en la actividad económica de corto plazo son, según se verá, ambiguos.

Como lo refleja la naturaleza de muchas de las intervenciones mencionadas, ellas estuvieron íntimamente ligadas al segundo componente de la política macroeconómica cuyo foco de atención fue el crecimiento a largo plazo: la estrategia de industrialización. La concepción fundamental que yacía tras esta política es la visión del crecimiento como un proceso de cambio estructural, en que los sectores primarios dan paso a las actividades industriales y de servicios modernos y donde la industria desempeña el papel fundamental como mecanismo de transmisión del progreso técnico originado en el centro — proceso que en la visión de Prebisch era "lento e irregular".

La gran paradoja que este proceso encarna estuvo siempre vinculada a las complejidades de su manejo en economías cuyas ventajas comparativas estáticas yacían claramente en la producción de bienes primarios. En las visiones clásicas cepalinas, la conveniencia de la estrategia de industrialización estuvo relacionada con la tendencia al deterioro secular de los precios de los productos básicos, idea que no ha sido corroborada, al menos no en la forma en que fue formulada entonces ${ }^{1}$. Una justificación mucho más sólida se deriva precisamente de las diferentes capacidades que tienen distintos sectores de la economía para transmitir progreso técnico y generar, al mismo tiempo, nuevos conocimientos. La justificación clásica de la industrialización no requería, en otras palabras, de la tendencia al deterioro de los precios de los productos básicos. Durante la década de 1930 o en la inmediata posguerra, la defensa de la industrialización era además obvia, porque el colapso de la economía mundial no ofrecía posibilidades muy diferentes a las que permitían los mercados internos.

Cabe resaltar que, en esta visión, que encarnó ante todo el "manifiesto latinoamericano", como denominó Albert Hirschman al informe de la CEPAL de 1949 (Prebisch, 1973), la solución no era aislarse de la economía internacional, sino redefinir la división internacional del trabajo para que los países latinoamericanos pudieran beneficiarse del cambio tecnológico que, con mucha razón, se veía estrechamente ligado a la industrialización. En otras palabras, lo que se proponía la

\footnotetext{
${ }^{1}$ La evidencia empírica muestra que en el siglo XX (aunque no en el XIX) hubo un deterioro, pero no de carácter secular, sino como un desplazamiento adverso que tuvo lugar durante dos coyunturas críticas, en torno de 1920 y en el decenio de 1980 (Ocampo y Parra, 2010).
}

estrategia de industrialización era crear nuevas ventajas comparativas. Aun más, las políticas de industrialización variaron a lo largo del tiempo, en parte para corregir sus propios excesos y en parte para responder a las nuevas oportunidades exportadoras que comenzó a brindar la economía mundial desde la década de 1960. Por ello, a partir de ese decenio la visión cepalina evolucionó de la sustitución de importaciones — de la que criticó sus excesos-a un modelo "mixto" en que se combinaba la sustitución de importaciones con la diversificación de las exportaciones y los procesos de integración regional ${ }^{2}$. Ello se materializó en la región con la generalización de políticas de promoción de exportaciones, la racionalización parcial de la compleja estructura de protección arancelaria y pararancelaria, la simplificación o eliminación de los regímenes de tipo de cambio múltiple, y la incorporación de esquemas de devaluación gradual en las economías con tradición inflacionaria ${ }^{3}$.

Un problema inherente a la intersección entre los determinantes de los ciclos y la estrategia de largo plazo es la dificultad para mantener esa estrategia ante los cambios en los precios relativos que generan los ciclos de origen externo. En efecto, los auges de precios de los productos básicos tienden a producir incentivos a la re-primarización de las estructuras productivas, tanto por la vía de los precios internacionales como de los efectos que los auges de precios provocan en el tipo de cambio. Ambos tienden a reducir los precios relativos de las exportaciones manufactureras y de la producción industrial destinada al mercado interno. Los auges de capitales coinciden con frecuencia con los de precios de los productos básicos, que tienen efectos similares en el tipo de cambio. Para manejar los de productos básicos surgieron históricamente instrumentos de intervención, en especial impuestos a los productos primarios de exportación, tipos de cambio discriminatorios en su contra e incentivos a las exportaciones no tradicionales. Para manejar los ciclos de financiamiento se diseñaron los controles de capitales. La desaparición de muchos de estos instrumentos dio lugar más tarde a nuevos desafíos, a lo que cabe agregar que los gobiernos sucumbieron con excesiva frecuencia a la tentación de seguir e incluso reforzar, en vez de atenuar, los efectos de los ciclos externos.

\footnotetext{
2 Véanse, al respecto, diversas historias del pensamiento cepalino (Bielschowsky, 1998; Rodríguez, 2006; Rosenthal, 2004) y la revisión del primer medio siglo del Estudio económico de América Latina y el Caribe (CEPAL, 1998c),

${ }^{3}$ Véanse Ffrench-Davis, Muñoz y Palma (1998); Ocampo (2004); Bértola y Ocampo (2010).
} 
La estrategia de industrialización conllevaba muchos otros elementos. Entre ellos se destaca la necesidad de elevar la tasa de inversión, tanto en la industria como en la infraestructura física. De ahí surgieron la demanda de financiación externa multilateral así como el desarrollo de instrumentos internos apropiados, entre los que se destacan la banca de desarrollo y la inversión directa del Estado en infraestructura y en algunas actividades industriales, esta última muy variable a lo largo y ancho de la región. Por motivos de espacio, estos temas no serán analizados en este ensayo.

También se dejará de lado otra contribución, que ocupó un lugar en los debates de aquellos años y se refiere a la dinámica de la inflación. En la visión estructuralista, formulada en forma pionera por Noyola (1956) y Sunkel $(1958)^{4}$, se distingue entre los choques inflacionarios básicos y los mecanismos de propagación de la inflación. En la elaboración posterior, vinculada a las teorías de la “inflación inercial”, los choques inflacionarios básicos operan prioritariamente como perturbaciones en el tipo de cambio o en los precios de los alimentos, y los mecanismos de propagación inflacionaria se relacionan fundamentalmente con procedimientos de indización de precios, especialmente de los salarios, del tipo de cambio (en los sistemas de devaluación gradual) y de los costos financieros. El resultado de esta dinámica es que los choques en los precios de los productos básicos generan un aumento en la tasa de inflación, que se torna permanente a consecuencia de la indización. Por ello, dichas perturbaciones pueden dar lugar a una elevación permanente de los ritmos de inflación, que puede variar nuevamente en función de nuevos choques y, por lo tanto, todo ritmo de inflación es siempre un equilibrio inestable. Por lo tanto, la única forma de reducirla es, a la postre, estabilizar los precios básicos y eliminar los mecanismos de indización, como lo señalaron los experimentos heterodoxos de estabilización inflacionaria del decenio de 1980. Su éxito o fracaso se relacionó con los efectos de demanda agregada ligados a estos procesos inflacionarios. En efecto, este tipo de dinámica inflacionaria es recesiva por la vía de la demanda agregada, y el freno a la inflación es, por el contrario, expansionista; de modo que la estabilización inflacionaria solo tiene éxito cuando se contrarrestan al mismo tiempo estos efectos expansivos (Taylor, 1991, cap. 4) ${ }^{5}$.

\footnotetext{
${ }^{4}$ Véase también el aporte un poco más tardío de Olivera (1964).

${ }^{5}$ Como se desprende de los aportes de Taylor (1991) y otros autores, los efectos de demanda agregada operan fundamentalmente a través de las diferentes propensiones a consumir (o, más en general, a gastar) de los distintos agentes económicos. Así, la aceleración inflacionaria
}

Cabe agregar que estas ideas se desarrollaron mucho más tempranamente respecto de teorías similares de corte keynesiano, en las que el foco de atención fue la persistencia de las expectativas de inflación y cuyas implicaciones de política eran muy diferentes, ya que el foco se desplazó hacia la "credibilidad" de las políticas antinflacionarias. En algunos casos las dos escuelas se encuentran, sobre todo cuando la desaceleración inflacionaria debe contar con el desmonte de los mecanismos de indización (una concesión del enfoque ortodoxo a las teorías estructuralistas) y cuando se torna necesario adoptar políticas restrictivas de demanda para el éxito de las políticas heterodoxas de estabilización inflacionaria (una concesión de estas teorías al enfoque ortodoxo).

\section{Las contribuciones de las dos últimas décadas}

A partir del documento pionero Transformación productiva con equidad. La tarea prioritaria del desarrollo de América Latina y el Caribe en los años noventa (CEPAL, 1990), tuvo lugar una verdadera reconstrucción del pensamiento cepalino que, con variantes, ha mostrado una gran continuidad a lo largo de los dos últimos decenios. Uno de los elementos centrales ha sido la persistencia en la promoción de la equidad y, más aún, de la igualdad, especialmente de aquella que se refiere a los derechos ciudadanos, idea que subyace en el último documento institucional La hora de la igualdad: brechas por cerrar, camino por abrir (CEPAL, 2010a), así como —al cambio de siglo- en Equidad, desarrollo y ciudadanía (CEPAL, 2000). Nuevamente, el espacio no permite hacer debida justicia al gran esfuerzo por establecer claras conexiones entre la política económica y sus resultados sociales, y enfocar la atención en las contribuciones más estrechamente relacionadas con el manejo anticíclico y el cambio estructural.

Con respecto al manejo anticíclico, la CEPAL (1998b) formuló, como parte de un paquete más amplio de medidas orientadas a diseñar un nuevo pacto fiscal, la necesidad de morigerar el carácter procíclico que en general siguieron mostrando las finanzas públicas latinoamericanas en el decenio de 1990. La principal propuesta cepalina consistía en aislar los componentes cíclico y estructural de las finanzas públicas, tanto por parte de los gastos como de los ingresos, y definir las metas fiscales en función de reglas estructurales. Esta

beneficia a los receptores de rentas de capital y la estabilización a los de rentas de trabajo. 
propuesta, que en los recientes debates se ha acogido a nivel internacional, se distanciaba de las leyes de responsabilidad fiscal entonces en boga, orientadas más bien a fijar metas sobre el déficit fiscal corriente o relaciones máximas de endeudamiento público. Estas normas, sugeridas entonces por los organismos financieros internacionales e incluso acogidas por la Unión Europea en el Tratado de Maastricht, son por naturaleza procíclicas.

En materia de ingresos, la CEPAL proponía que los ingresos fiscales transitorios, tanto aquellos vinculados a recursos naturales como al componente cíclico de los ingresos tributarios en general, se acumularan en fondos de estabilización para evitar que se gastaran en los períodos de auge y estuvieran disponibles para financiar el gasto público durante las crisis. Señalaba, además, la necesidad de contabilizar adecuadamente los gastos cuasi fiscales, ligados tanto a las garantías otorgadas al sistema financiero como a la cobertura de los riesgos de inversiones privadas en infraestructura. Ambos son por naturaleza procíclicos, porque tales gastos contingentes se incurre (o son causados) durante los auges, aunque se hacen efectivos durante las crisis, muchas veces desplazando a otro tipo de gastos.

El otro tema de corto plazo que se destacó en varios documentos, particularmente en CEPAL (1998a y 2000), se relacionó con el manejo de los ciclos de financiamiento externo, cuyos estragos ya se habían sentido en la región. En términos de política económica, la principal recomendación era la necesidad de vigilar la evolución de los tipos de cambio reales a fin de evitar la sobrevaluación durante los períodos de auge. En sentido contrario a la tendencia entonces en boga de considerar que los regímenes cambiarios deberían ser extremos (ya sea plenamente flexibles o tipos de cambio fijos con reglas rígidas, como la dolarización o el sistema de convertibilidad que entonces se adoptó en la Argentina), la CEPAL se inclinó por regímenes cambiarios intermedios, de flexibilidad administrada. Propuso, además, moderar los ciclos de financiamiento externo con medidas orientadas a reducir los ingresos de capitales durante los períodos de euforia en los mercados financieros, utilizando entre otros los encajes al financiamiento externo que ya se venían empleando en Chile y Colombia.

La CEPAL (2000, Tomo III, cap. 1) fue un paso más adelante al sugerir que las regulaciones financieras internas fuesen también utilizadas como instrumentos anticíclicos. Esta propuesta implicaba que la regulación prudencial debería tener en cuenta no solo los riesgos microeconómicos, sino los macroeconómicos en que se incurría durante los períodos de auge crediticio. Para corregir los riesgos correspondientes, sugería aumentar los requisitos de capital y liquidez de las entidades financieras en los períodos de auge del crédito, corregir los descalces de monedas entre activos y pasivos que tendían a proliferar en los períodos de financiamiento externo abundante, e imponer límites a los valores de los activos que se podían utilizar como garantías de los créditos durante los períodos de inflación de activos. De esta manera, en la terminología que propuso poco después el Banco de Pagos Internacionales (BPI) y que se ha aceptado en forma generalizada durante la crisis reciente, la CEPAL se adelantó casi una década en proponer reglas "macroprudenciales" tanto para el manejo de la entrada de capitales como del crédito interno.

En materia de crecimiento económico, y en concordancia con lo planteado a partir del documento seminal de 1990, la CEPAL (1998a, 2000, 2007 y 2008a) propuso una agenda de desarrollo productivo para economías abiertas. El punto de partida de esa agenda, como de las teorías cepalinas más clásicas, es la concepción del desarrollo como un proceso de cambio estructural en que la dinámica se determina por la capacidad de desarrollar ramas productivas con mayores contenidos tecnológicos. Por este motivo, junto con la promoción de estructuras orientadas a resguardar la competencia y políticas "horizontales" dirigidas a corregir las fallas que caracterizan a los mercados de factores ${ }^{6}$, la CEPAL propuso una serie de políticas destinadas a desarrollar estructuras productivas más dinámicas, que incluían el fomento de actividades innovadoras con mayor contenido tecnológico (redes nacionales de innovación) y la promoción de exportaciones (diversificación de la oferta exportadora, encadenamientos internos de la actividad exportadora y conquista de nuevos mercados). Se incluían también propuestas dirigidas a desarrollar las sinergias y complementariedades que generan entre sí los sectores productivos y que producen "competitividad sistémica", para utilizar el concepto germen que se había propuesto en Transformación productiva con equidad.

Este último grupo de políticas se enfrentaban entonces, y en general continúan enfrentando, al vacío institucional resultante del desmantelamiento de los mecanismos de intervención en el desarrollo productivo que se habían creado en la región durante la fase de industrialización dirigida por el Estado. La CEPAL

\footnotetext{
${ }^{6}$ Dichas políticas se refieren al acceso a capital de largo plazo y, más en general, a crédito en el caso de las pequeñas y medianas empresas (pymes), así como a tecnología, recursos humanos calificados y tierra.
} 
señalaba que estos marcos podían reconstruirse mediante un conjunto de alianzas público/privadas que cada país debería desarrollar siguiendo sus propios senderos evolutivos. La destrucción de las instituciones previas y la falta de esfuerzos por construir otras nuevas eran vistas como causantes de la fragilidad de las estructuras productivas que continuaban caracterizando a la región. Un elemento que, además, ataba esta estrategia al manejo macroeconómico de corto plazo, fue la obsesión por mantener tipos de cambio competitivos, que se consideraban esenciales para una activa política de diversificación productiva.

Los recientes debates económicos parecen haber validado las visiones cepalinas del manejo macroeconómico de corto plazo. La aceptación generalizada en los últimos años de estrategias de innovación muestra también la validez de la visión que propugnó defendió la CEPAL durante la etapa de industrialización latinoamericana y que continuó defendiendo y adaptando a las nuevas condiciones del desarrollo regional.

\section{III}

\section{Las políticas anticíclicas}

\section{Las modalidades contemporáneas del "predo- minio de la balanza de pagos"}

El comercio internacional sigue teniendo una importante incidencia en la dinámica de la balanza de pagos de los países en desarrollo y de los latinoamericanos en particular. Esto es especialmente evidente con respecto a los términos de intercambio en el caso de los productores de productos básicos. La reciente crisis evidenció asimismo que los volúmenes de exportaciones de manufacturas y servicios (sobre todo de turismo, el renglón más importante en la región) son procíclicos. A los problemas vinculados a los precios de los productos básicos, cuya incidencia continúa siendo acentuada en los países latinoamericanos, se hará referencia más adelante.

No obstante la importancia de estas variables comerciales, la característica más destacada desde el decenio de 1970 ha sido el papel central que desempeña la cuenta de capitales en la determinación de las fluctuaciones económicas de los países en desarrollo, en particular de aquellos (cada vez más numerosos) que tienen acceso a los mercados privados de financiamiento internacional. Más aún, si bien una parte relevante de la inestabilidad que generan los ciclos de financiamiento externo se transmite a través de las cuentas públicas - como fue especialmente importante en América Latina en los decenios de 1970 y 1980 la característica dominante en las últimas décadas han sido las fuertes fluctuaciones en los gastos y balances privados ligados a los ciclos de financiamiento externo. Una consecuencia de ello ha sido la proliferación de “crisis gemelas" desde la década de 1970, en las que se combinan crisis financieras externas e internas. Las del
Cono Sur, de comienzos del decenio de 1980, fueron pioneras en su género.

Este fenómeno es, por supuesto, la manifestación de un problema más general: la tendencia de los sectores financieros a experimentar ciclos de auge y colapso, tema que ocupó un lugar central en las concepciones que rodearon a la revolución keynesiana y que fue desarrollado con especial agudeza analítica por Minsky (1982). A nivel empírico, los trabajos ya clásicos de Kindleberger (véase Kindleberger y Aliber, 2005), el más reciente de Reinhart y Rogoff (2009) y, en relación con las economías emergentes y América Latina, los de Agosin y Huaita (2009) y Ffrench-Davis y Griffith-Jones (2011), entre otros, corroboran este patrón de comportamiento. Sus características medulares son la volatilidad y el contagio. A lo largo del ciclo, los agentes financieros alternan entre el "apetito por el riesgo" (o quizás, más correctamente, la subestimación de riesgos) y la "fuga hacia la calidad" (aversión al riesgo) y las percepciones y expectativas se retroalimentan, generando primero un contagio de optimismo y posteriormente un contagio de pesimismo. Las asimetrías de información que caracterizan a los mercados financieros, los modelos de evaluación de riesgos, así como ciertas prácticas del mercado (el "referenciamiento" competitivo, en particular), tienden a acentuar estas tendencias.

Los ciclos son particularmente drásticos para aquellos agentes del mercado considerados más "riesgosos", que por lo tanto reciben financiamiento abundante en los períodos de auge, pero experimentan, a su vez, bruscas interrupciones de dicho financiamiento durante las fases descendentes del ciclo. Estos agentes son las pequeñas y medianas empresas y los hogares de menores recursos en 
todos los países, así como las economías emergentes y en desarrollo en los mercados internacionales ${ }^{7}$. Una forma adecuada de interpretar este último fenómeno es que la integración financiera del mundo en desarrollo fue segmentada, es decir, se trató de una integración a un mercado que está segmentado por categorías de riesgo, en las que los países en desarrollo están clasificados como riesgosos y sujetos, por ello, a perturbaciones cíclicas particularmente intensas (Frenkel, 2008).

A consecuencia de ello, los países experimentan fases de auge y crisis, con cierta independencia de los "fundamentos macroeconómicos" (Calvo, Leiderman y Reinhart, 1993; Calvo y Talvi, 2008). Los países considerados "exitosos" son atraídos con especial fuerza al auge, lo que tiende a inducir elevados déficits privados que posteriormente pueden convertirse en formas de vulnerabilidad (Ffrench-Davis, 2005; Marfán, 2005). Debido a ello, economías consideradas exitosas pueden transformarse más tarde en parias de la comunidad financiera internacional.

La volatilidad se refleja en el comportamiento de los márgenes de riesgo, así como en disponibilidad y plazos de financiamiento, que tienen efectos procíclicos. Además, los riesgos tienden a acentuarse a causa de los problemas de desarrollo financiero de los países en desarrollo, que se reflejan en una proliferación de descalces de moneda y de plazos en las hojas de balance de las empresas. Aunque todas las formas de financiamiento tienden a ser procíclicas, este patrón de comportamiento es más acentuado en el financiamiento de corto plazo que, por lo tanto, resulta sobre todo riesgoso (Rodrik y Velasco, 2000). La inversión extranjera directa tiene, por el contrario, un comportamiento algo más estable.

Aunque los movimientos intensos de corto plazo son particularmente traumáticos, como los acontecidos a raíz de la moratoria rusa de agosto de 1998 o la quiebra de Lehman Brothers de septiembre de 2008, un problema incluso más importante lo representan las fluctuaciones de mediano plazo. Desde mediados del decenio de 1970 se han experimentado tres ciclos de este tipo, y podemos estar en el inicio de un cuarto ciclo: auge durante el segundo lustro de la década de 1970, seguido de crisis en el decenio de 1980; auge en 1990-1997 (interrumpido brevemente por la crisis mexicana de diciembre de 1994), sucedido por la secuencia de la crisis asiática y de otras economías emergentes a partir de 1997; auge entre 2003

\footnotetext{
${ }^{7}$ El concepto de "economías emergentes" carece de una definición precisa. Por eso, en este trabajo se agrupan los países que se consideran parte de esta categoría dentro de la definición más amplia de países en desarrollo.
}

y mediados de 2008, seguido de la fuerte contracción posterior a la quiebra de Lehman Brothers; e inicio de un nuevo auge a mediados de 2009.

En el gráfico 1 se observa la evolución de los márgenes de riesgo desde 1997 hasta hoy. La mayor intensidad y duración de la perturbación iniciada con la crisis de la moratoria rusa de agosto de 1998 son notorias cuando se comparan con la crisis reciente. Una explicación de ello es que la duración de las crisis se relaciona directamente con la magnitud de las intervenciones de los países industrializados orientadas a contenerla. Es por eso que la crisis mexicana de diciembre de 1994 no tuvo repercusiones amplias en el mundo en desarrollo, ni las tuvo la reciente crisis financiera internacional. Otra explicación complementaria es la mejoría en las políticas macroeconómicas, que ha reducido la vulnerabilidad externa de las economías emergentes. Ello contribuyó a la drástica reducción de los márgenes de riesgo que experimentaron las economías emergentes entre 2004 y 2007, que llegaron a su mínimo histórico poco antes del estallido de la crisis de las hipotecas de baja calidad en los Estados Unidos en agosto de 2007, así como, y especialmente, a la menor intensidad de la crisis desatada con la quiebra de Lehman Brothers. En tal sentido, los eventos en los mercados financieros internacionales ocurridos desde mediados del decenio pasado pueden entenderse como una disminución de la segmentación de los mercados que había caracterizado a las décadas precedentes, vinculada a la mejoría en las políticas macroeconómicas (Frenkel, 2010).

Los problemas que plantean estos ciclos de mediano plazo se relacionan no solo con el comportamiento procíclico del gasto privado, sino también con las presiones para adoptar políticas económicas procíclicas y con la reducción de la efectividad de las políticas anticíclicas. Como veremos, este problema es muy notorio en el caso de la política monetaria. De hecho, la efectividad limitada y las restricciones que enfrentan las diferentes políticas hacen que sea especialmente importante contar con una amplia gama de instrumentos. Esto último, además, reviste especial relevancia porque la estabilidad macroeconómica —el objetivo esencial de las políticas anticíclicas - no involucra únicamente al nivel de precios (concepto al que en muchos análisis se restringe el concepto de estabilidad), sino también la estabilidad financiera y la estabilidad de la actividad económica y el empleo (estabilidad real).

De hecho, mientras se ha avanzado bastante en reducir la inflación y, durante la reciente fase de turbulencia, en evitar crisis financieras nacionales, se ha mermado menos de lo deseable la intensidad de 
GRÁFICO 1

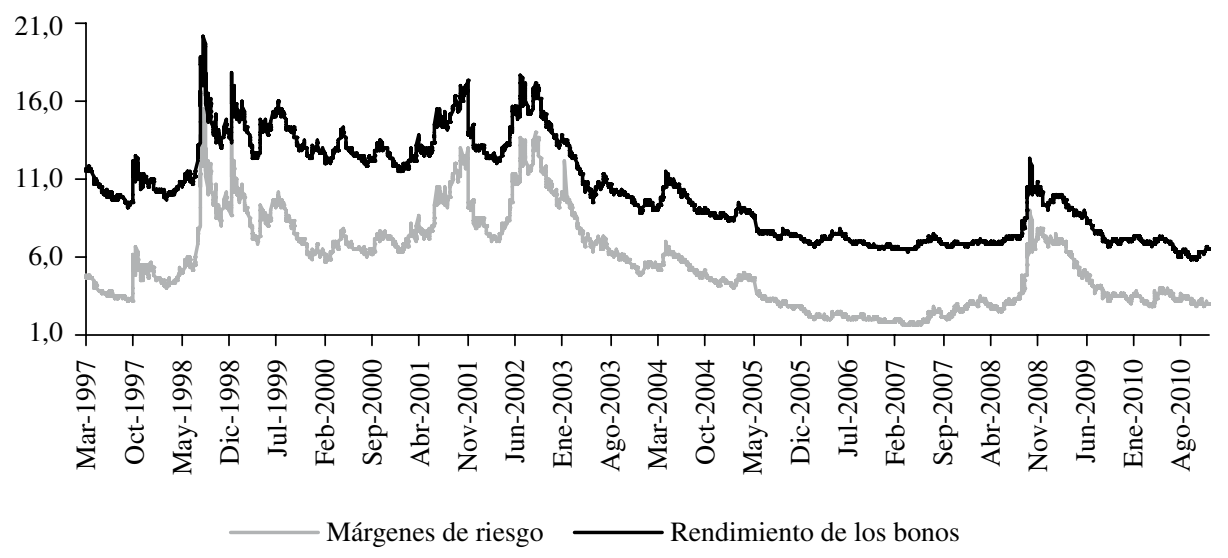

Fuente: J.P. Morgan.

GRÁFICO 2

América Latina: crecimiento del PIB, 1975-2011

(En porcentajes)

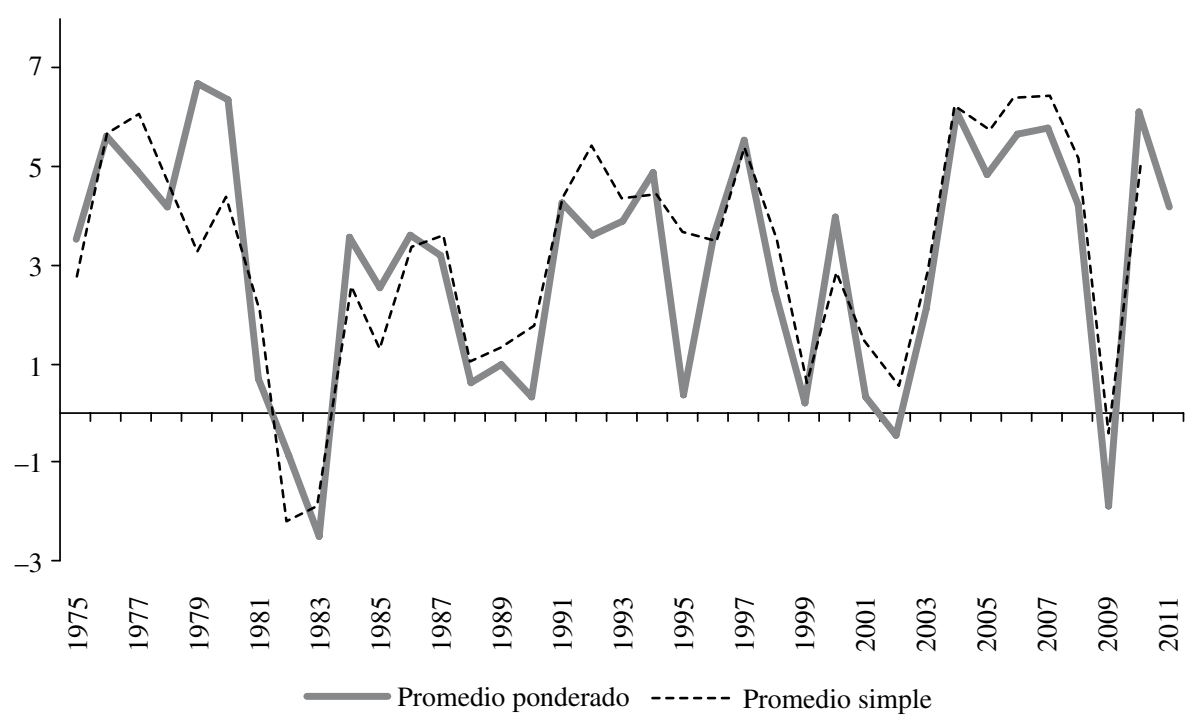

Fuente: estimaciones del autor sobre la base de datos de la Comisión Económica para América Latina y el Caribe (CEPAL).

PIB: producto interno bruto.

los ciclos económicos. En este último sentido, cabe destacar que la recesión de 2009 fue pronunciada en la región, registrándose la peor caída del producto interno bruto (PIB) desde el año 1983, tanto si se estima como el crecimiento ponderado, o como el promedio simple de los ritmos de crecimiento de las distintas economías latinoamericanas, lo que indica que fue generalizada (véase el gráfico 2). Además, este desempeño fue peor que el experimentado por otras regiones del mundo en desarrollo, con excepción de los países de Europa central y oriental (Ocampo y otros, 2010), aunque la recuperación ha sido vigorosa, 
especialmente en las economías de América del Sur. De ahí la importancia de seguir avanzando en el diseño de políticas anticíclicas.

En las páginas que siguen se analizan tres conjuntos de políticas en términos de su contribución a la estabilización del ciclo económico: las fiscales; las monetarias y cambiarias, que por su interrelación se analizan conjuntamente; y un tercer grupo que abarca lo que, de acuerdo con la terminología sugerida por Epstein, Grabel y Jomo (2003), pueden denominarse técnicas de administración financiera (capital management techniques) (Ocampo, 2008), pero que aquí se denominarán macroprudenciales, para emplear la terminología reciente.

\section{Políticas fiscales anticíclicas}

En economías abiertas, la política monetaria encuentra serias dificultades para cumplir su papel anticíclico, especialmente cuando se ha abierto la cuenta de capitales. Por este motivo, el mejor instrumento de manejo anticíclico es indudablemente la política fiscal. En países donde las fluctuaciones de los precios de los productos básicos son una de las fuentes básicas de los movimientos cíclicos, una alternativa es establecer fondos de estabilización. El ejemplo más importante en años recientes es el de Chile, así como en el pasado lo fue el Fondo Nacional del Café de Colombia. Sobre la base de estas experiencias y de acuerdo con la recomendación de la CEPAL (1998b), sería conveniente pensar en fondos de estabilización de ingresos públicos de mayor alcance, que capten los componentes transitorios del conjunto de dichos ingresos.

De manera más general, como también se señaló en el documento de la CEPAL y se ha venido practicando en Chile, lo deseable es establecer reglas estructurales para el manejo de las finanzas públicas que aíslen tanto los componentes cíclicos de los ingresos como del gasto público. Esto no es, desde luego, una tarea fácil, entre otras razones porque la tendencia del PIB puede no ser independiente del ciclo en economías sujetas a acentuadas perturbaciones cíclicas (Heymann, 2000) y, en el caso de los precios de los productos básicos, porque estos siguen muchas veces "paseos aleatorios", es decir, cambios de niveles que se tornan permanentes.

En todo caso, lo que las reglas estructurales implican es que el gasto público debe guiarse esencialmente por su tendencia de largo plazo. En términos estrictos, esta regla es neutral frente al ciclo económico (o acíclica), por lo que debe estar acompañada de gastos de carácter estrictamente anticíclico ${ }^{8}$. Sin embargo, para evitar rezagos en la respuesta de la política fiscal, lo mejor es contar con componentes del gasto que respondan automáticamente a las variaciones del ciclo económico.

En este sentido, la experiencia en los países industrializados indica que lo más conveniente es contar con estabilizadores automáticos ligados a la protección social. Aunque los seguros de desempleo cumplen ese papel en dichos países, no constituyen necesariamente el mecanismo más apropiado para las economías en desarrollo, donde el empleo informal tiene una alta participación en la generación de puestos de trabajo. Por ello, puede ser conveniente utilizar instrumentos adicionales, en particular mecanismos de empleo de emergencia que se activan automáticamente durante las crisis. Los subsidios condicionados fueron también utilizados con este propósito por varios países latinoamericanos en la crisis reciente, pero es difícil pensar que puedan reducirse durante los auges, como lo exige un buen instrumento anticíclico.

Nótese que, aparte del gasto, los instrumentos de tributación pueden también diseñarse con objetivos anticíclicos. El mejor instrumento es un impuesto de renta progresivo, que tiene las características de estabilizador automático. También puede ser conveniente diseñar otros instrumentos tributarios que tengan este carácter, como por ejemplo, mecanismos que capten directamente parte de los precios excepcionales de los productos básicos, en particular para alimentar los ya mencionados fondos de estabilización. Un argumento similar puede servir para justificar los impuestos a la entrada de capitales durante los períodos de auge crediticio. Téngase en cuenta que este argumento es de carácter fiscal y, por ende, adicional a los de carácter monetario y cambiario para establecer este tipo de impuestos, los que se analizarán más adelante. Con igual lógica también podría pensarse en diseñar un impuesto sobre el valor agregado (IVA) con tasas que varían a lo largo del ciclo económico. Una alternativa, utilizada en algunos países de la región durante la reciente crisis, fueron los recortes temporales de impuestos para incentivar la demanda.

Las políticas fiscales anticíclicas enfrentan, en cualquier caso, restricciones para su instrumentación, tanto de carácter económico como político. En términos económicos, los problemas más importantes son la falta de acceso al financiamiento durante los períodos recesivos, así como las presiones de los mercados (y

\footnotetext{
${ }^{8}$ Véase, por ejemplo, el análisis de Ffrench-Davis (2010) sobre los mecanismos fiscales chilenos.
} 
posiblemente del Fondo Monetario Internacional (FMI), aunque en esto ha habido cambios durante los últimos años) para adoptar políticas de austeridad fiscal que generen "credibilidad" en los mercados, es decir, den señales de que no hay riesgo de incumplimiento de las obligaciones crediticias. Si las autoridades se ven obligadas a adoptar políticas de austeridad, será entonces muy difícil justificar políticamente su mantenimiento cuando las condiciones económicas mejoran. De esta manera se genera un círculo vicioso, en que la austeridad durante las crisis es sucedida de aumentos del gasto durante la recuperación, generando un patrón procíclico de las finanzas públicas.

A su vez, durante los auges no es fácil justificar medidas de austeridad como mecanismo compensatorio de la "exuberancia" del gasto privado y, en particular, de una dinámica expansiva del gasto de los sectores de mayores ingresos (Marfán, 2005). Esto es sobre todo importante si los recortes afectan a rubros de gasto que tienen un impacto social progresivo y, en consecuencia, la política fiscal anticíclica se visualiza como regresiva. Además, pueden existir problemas clásicos de inconsistencia temporal en la forma como funcionan las decisiones políticas. En especial, el ahorro de recursos durante los auges puede generar presiones para gastarlos (la presión que enfrentó Chile durante el auge que precedió a la crisis internacional) o incluso dilapidarlos bajo la forma de reducciones insostenibles o inconvenientes de la tributación (como de hecho aconteció en los Estados Unidos después de los excedentes fiscales generados durante la era Clinton).

Debe agregarse que el manejo anticíclico de los gastos públicos puede generar ineficiencias (por ejemplo, interrupciones en obras públicas durante los períodos de auge que aumentan su costo) o inflexibilidades de largo plazo (ampliaciones del gasto social o recortes de impuestos durante las crisis que se tornan permanentes). Además, por motivos estrictamente políticos, puede ser difícil diseñar normas tributarias anticíclicas, como lo atestigua en particular la resistencia a imponer aumentos de tributación a los exportadores de productos básicos en los períodos de auge.

Por este conjunto de razones, la evidencia indica que las políticas fiscales anticíclicas son la excepción más que la regla en el mundo en desarrollo. En el análisis de Kaminsky, Reinhart y Végh (2004) sobre el comportamiento cíclico del gasto público en más de un centenar de países durante el período 1960-2003, se señala en efecto que las políticas fiscales han tendido a ser procíclicas en los países en desarrollo, especialmente en África y América Latina, a diferencia de los países industrializados. Sobre la base de estos estimativos, Ocampo y Vos (2008, cap. IV) han mostrado que este patrón procíclico se relaciona con un menor crecimiento a largo plazo de los países. Respecto de América Latina, Martner y Tromben (2003) llegan a la conclusión de que los episodios procíclicos son más frecuentes que los de políticas neutrales y anticíclicas en el período 1990-2001. Este mismo resultado es corroborado por Bello y Jiménez (2008) para el período 1990-2006. Asimismo, el carácter procíclico del gasto social ha sido un tema recurrente en los análisis del Panorama social de América Latina de la CEPAL (véase, por ejemplo, CEPAL, 2010b).

Por lo demás, no es evidente que en esta materia haya habido mejorías sistemáticas en épocas recientes: hay países que han tendido a adoptar políticas anticíclicas, pero los patrones procíclicos tienden todavía a predominar $^{9}$. En el gráfico 3 se observa para el conjunto de la región un patrón que ha sido característico durante los dos últimos decenios: sobre niveles moderados de déficit (lo que indica que este no es un logro de años recientes, sino de los ajustes efectuados durante la década perdida), el gasto primario muestra un comportamiento procíclico con un rezago de uno o dos años. El patrón puede describirse aproximadamente de la siguiente manera: durante la fase de auge, la recuperación de los ingresos antecede a la del gasto primario, pero este toma forma con fuerza al final del auge (2006-2008, durante el auge reciente); la dinámica expansiva del gasto continúa durante la fase inicial de la crisis (2009, y también en 1999), pero es seguida poco después por una menor dinámica del gasto para reducir los desequilibrios fiscales. De esta manera, los rezagos generan un aparente comportamiento anticíclico durante las fases iniciales del auge y la crisis, pero el patrón prevaleciente es en realidad procíclico. Más aún, un análisis del ciclo reciente a nivel de los países denota claramente que los países que han seguido un patrón anticíclico del gasto primario son la excepción más que la regla. Lo más común ha sido un comportamiento procíclico, y en el cuadro 1 se clasifican varios países en un tercer grupo de comportamiento expansivo durante ambas fases del ciclo.

Pese a los avances que ya se han logrado en materia de disciplina fiscal - que, como se ha señalado, son ya de antigua data - y a la reducción virtualmente

\footnotetext{
${ }^{9}$ Véanse, entre otros, BID (2008); CEPAL (2008b, cap. IV); y Ocampo (2007) para el auge que precedió a la reciente crisis, o FMI (2010, cap. 4) para el conjunto del ciclo más reciente.
} 
GRÁFICO 3

América Latina: ingresos y gasto primario del sector público, 1990-2010 (En porcentajes del PIB)

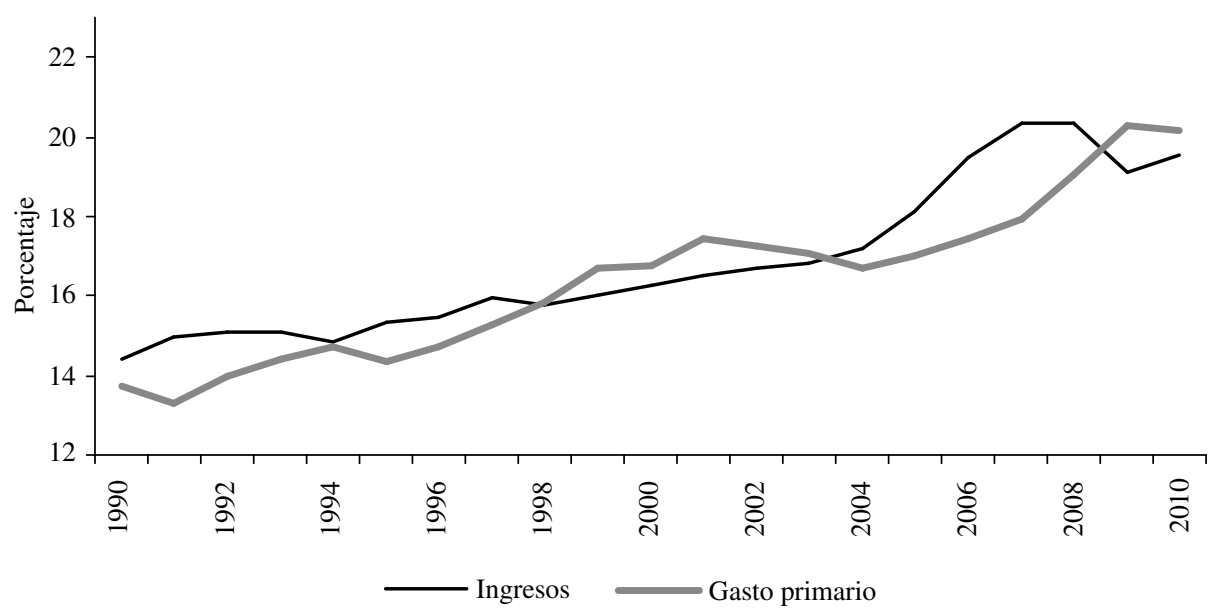

Fuente: estimaciones del autor sobre la base de datos de la Comisión Económica para América Latina y el Caribe (CEPAL).

PIB: producto interno bruto.

CUADRO 1

América Latina: caracterización del gasto público

\begin{tabular}{|c|c|c|c|c|c|c|}
\hline & & \multicolumn{3}{|c|}{$\begin{array}{l}\text { Crecimiento real del gasto } \\
\text { primario en porcentajes }\end{array}$} & \multicolumn{2}{|c|}{$\begin{array}{l}\text { Crecimiento del gasto } \\
\text { 2004-2008 vs } \\
\text { crecimiento del PIB en: }\end{array}$} \\
\hline & & 2004-2008 & 2009 & 2010 & 2004-2008 & $1990-2010$ \\
\hline \multicolumn{7}{|l|}{ Anticíclicos } \\
\hline & Chile & 5,5 & 15,3 & 4,4 & 1,15 & 1,10 \\
\hline & El Salvador & 1,6 & 10,8 & 5,1 & 0,49 & 0,47 \\
\hline & Paraguay & 2,0 & 28,0 & 11,4 & 0,42 & 0,73 \\
\hline & Perú & 7,3 & 12,7 & 12,6 & 0,96 & 1,66 \\
\hline \multicolumn{7}{|l|}{ Acíclicos con expansión moderada } \\
\hline & Guatemala & 2,3 & 4,6 & 3,3 & 0,52 & 0,62 \\
\hline \multicolumn{7}{|l|}{ Acíclicos con expansión persistente } \\
\hline & Argentina & 12,3 & 19,7 & 14,5 & 1,46 & 3,03 \\
\hline & Colombia & 7,7 & 10,9 & $-4,2$ & 1,41 & 2,21 \\
\hline & Costa Rica & 7,6 & 10,6 & 3,3 & 1,29 & 1,61 \\
\hline & Uruguay & 7,0 & 7,4 & 10,7 & 0,84 & 2,02 \\
\hline \multicolumn{7}{|l|}{ Procíclicos } \\
\hline & Bolivia (Estado Plurinacional de) & 10,2 & 0,2 & 10,2 & 2,12 & 2,67 \\
\hline & Brasil & 7,9 & 2,2 & 10,6 & 1,67 & 2,91 \\
\hline & República Dominicana & 11,7 & $-12,1$ & 0,7 & 1,67 & 2,26 \\
\hline & Ecuador & 19,7 & 6,0 & 7,4 & 3,66 & 6,34 \\
\hline & Honduras & 8,1 & 3,5 & $-3,8$ & 1,38 & 2,29 \\
\hline & México & 5,7 & 3,4 & $-3,6$ & 1,71 & 2,05 \\
\hline & Nicaragua & 6,9 & 5,1 & 3,0 & 1,73 & 2,33 \\
\hline & Panamá & 12,8 & $-0,3$ & 6,3 & 1,46 & 2,26 \\
\hline & Venezuela (República Bolivariana de) & 12,6 & $-1,4$ & $-12,5$ & 1,22 & 4,28 \\
\hline & Promedio & 8,3 & 7,0 & 4,4 & 1,40 & 2,27 \\
\hline
\end{tabular}

Fuente: estimaciones del autor sobre la base de datos de la Comisión Económica para América Latina y el Caribe (CEPAL). 
generalizada de los coeficientes de endeudamiento público, queda mucho por hacer en el diseño de políticas fiscales anticíclicas y de instituciones que les sirvan de respaldo.

\section{Autonomía monetaria y cambiaria en economías con "predominio de la balanza de pagos"}

En la historia de las crisis del mundo en desarrollo en las últimas décadas se aprecia claramente lo correcto de la visión cepalina de que la dinámica económica de los países en desarrollo se caracteriza por un "predominio de la balanza de pagos" y, sobre todo en las décadas más recientes, por los ciclos de la cuenta de capitales. Es más, resalta categóricamente que uno de los problemas más relevantes es la presión que ejercen esos ciclos para que las políticas monetaria y cambiaria se comporten en forma procíclica. Esto es particularmente cierto respecto de la política monetaria, ya que las economías donde se ha abierto la cuenta de capitales enfrentan la presión para reducir tasas de interés durante los auges y aumentarlas durante las crisis. Cuando no ceden a dicha presión y las autoridades optan por una política anticíclica, simplemente desplazan el efecto hacia el tipo de cambio, es decir, hacia la revaluación durante los auges y la devaluación durante las crisis. Esto indica que las autoridades monetarias y cambiarias carecen efectivamente de autonomía y, de alguna manera, solo pueden elegir qué efecto procíclico prefieren ${ }^{10}$. Aunque esta afirmación debe ser vista con matices, ella capta un elemento sobresaliente de la dinámica monetaria y cambiaria en economías abiertas a la cuenta de capitales.

Cabe resaltar que las fluctuaciones del tipo de cambio generadas por los movimientos de capital tienen efectos ambiguos en el corto plazo y contraproducentes en el largo plazo. El principal efecto anticíclico opera a través de la cuenta corriente de la balanza de pagos, que tiende a deteriorarse durante los auges y a mejorar durante las crisis. Pero, más allá de cierto nivel, este patrón de comportamiento es contraproducente y, de hecho, la revaluación y el consecuente deterioro de la cuenta corriente durante los auges han sido la causa fundamental de las crisis en el pasado, ya que si bien ayudan a "absorber" el exceso de financiamiento durante los auges, se convierten en la principal fuente de

\footnotetext{
${ }^{10}$ Aquí hay alguna similitud con la afirmación clásica de Robert Mundell de que, en presencia de una tasa de cambio fijo, las autoridades no pueden controlar la cantidad de dinero, sino la composición entre activos nacionales y externos del banco central que respaldan la oferta monetaria.
}

vulnerabilidad de la economía cuando cambia la dirección de los movimientos de capitales. Por este motivo y por los efectos ambiguos que genera la volatilidad de la tasa de cambio en los patrones de especialización y crecimiento (tema que se retomará más adelante), en la literatura estructuralista se ha optado decididamente en contra de las ventajas de este mecanismo de ajuste, al menos más allá de cierto nivel ${ }^{11}$.

Conviene subrayar que este efecto de las fluctuaciones del tipo de cambio ha tendido a ser frecuentemente más débil que los efectos procíclicos que se generan por dos vías diferentes y que son los que contribuyen a la ambigüedad de las repercusiones del tipo de cambio en la demanda agregada y, por ende, a su utilización como instrumento anticíclico. El primero de estos efectos, y quizás el más importante, se produce por la vía de la incidencia de la tasa de cambio en las hojas de balance del sector privado en economías en que este sector es deudor neto del resto del mundo, como ha tendido a serlo en América Latina ${ }^{12}$. En esos casos, la revaluación inducida por la abundancia de los capitales durante los auges genera ganancias de capital que incrementan la demanda agregada; a su vez, la devaluación durante las crisis produce pérdidas de capital que tienen efectos recesivos. A estos efectos se agregan los de tipo distributivo, que han sido destacados en la literatura tradicional acerca de los impactos recesivos de la devaluación (Díaz-Alejandro, 1988, cap. 1; Krugman y Taylor, 1978). La forma más simple de visualizarlos es a través de la respuesta de los salarios reales: la revaluación tiende a aumentarlos, lo que provoca un efecto expansivo si la propensión a consumir ingresos salariales es alta; la devaluación durante las crisis genera el efecto contrario en los salarios, lo que tiende a profundizar la caída de la demanda agregada.

En la literatura macroeconómica tradicional se han captado las restricciones que enfrentan las autoridades económicas mediante lo que se conoce como el "trilema" de las economías abiertas, cuya implicación más importante es que en economías donde se ha abierto la cuenta de capitales, las autoridades pueden controlar el tipo de cambio o la tasa de interés, pero no ambos. En los años anteriores a la crisis, ello condujo a los defensores de esta visión a proclamar que los únicos regímenes cambiarios sostenibles (o "creíbles") eran

\footnotetext{
${ }^{11}$ Véanse, por ejemplo, Ffrench-Davis (2005); Frenkel (2007 y 2010); Ocampo (2003 y 2008); Ocampo, Rada y Taylor (2009) y Stiglitz y otros (2006).

12 También en las hojas de balance del sector público, pero aquí el efecto ya está incluido en el análisis de la subsección anterior.
} 
los de tipos de cambio enteramente flexibles —en que las autoridades eligen mantener la autonomía monetaria, pero renunciando enteramente a la cambiaria-o los de tipos de cambio fijos o administrados, en que se opta por la autonomía cambiaria, pero se renuncia a manejar la política monetaria. Es más, como los tipos de cambio fijos pero reajustables son susceptibles a movimientos especulativos desestabilizadores, lo mejor en este último caso — según esta visión - es optar por regímenes rígidos, como las cajas de conversión o la dolarización, con lo que en realidad se renuncia tanto a la autonomía monetaria como a la cambiaria.

Desde el punto de vista de este ensayo, el problema de la segunda de estas opciones es que es claramente procíclica y, sobre todo, cuando adopta la forma extrema y no genera credibilidad su colapso es caótico, como lo demostró la experiencia argentina a comienzos del siglo XXI o el colapso del patrón oro en muchos países en la década de 1930.

La opción de tipos de cambio flexibles con manejo activo de la política monetaria en regímenes de metas de inflación tiene, por el contrario, algunas virtudes anticíclicas, siempre y cuando (y, por lo tanto, en la medida en que) la demanda agregada interna sea el principal determinante de la inflación ${ }^{13}$. Sin embargo, las variaciones del tipo de cambio que este régimen permite tienden a tener efectos procíclicos en la demanda agregada por los motivos ya mencionados. Además, debido a la interrelación entre el tipo de cambio y la inflación, genera efectos que también tienden a ser procíclicos bajo un régimen puro de inflación objetivo: como la revaluación propende a disminuir el nivel de precios durante los auges, las tasas de interés no se reducen en la magnitud necesaria para contener el auge de la demanda; por el contrario, el efecto inflacionario de la devaluación hace que se adopte una política monetaria restrictiva durante las crisis. Por lo tanto, como señalan los teóricos de la inflación objetivo, no en vano un régimen estricto de este tipo tiende a provocar mayor volatilidad de la actividad económica (Svensson, 2000).

Obviamente, en un sistema "flexible" de inflación objetivo - en que también se tiene en cuenta el nivel de actividad económica - se corrigen en parte estos problemas, pero también se deben corregir los efectos que genera el tipo de cambio en el nivel de precios. Es

\footnotetext{
13 Bajo estas condiciones se da lo que en la macroeconomía se ha denominado la "coincidencia divina", según la cual lograr los objetivos de inflación garantiza también los de estabilizar la economía en su nivel de pleno empleo. Sobra decir que este resultado no se ha dado aún en la práctica en los países industrializados.
}

más, si la inflación tiene como determinante fundamental las perturbaciones externas y los mecanismos de indización, más que las fluctuaciones de la demanda agregada — como señala la teoría estructuralista—, los cimientos de la teoría de inflación objetivo como regla para el manejo de la política monetaria se desvanecen ${ }^{14}$. Por este motivo, es mucho más lógico reconocer, como lo hace implícitamente el régimen flexible de inflación objetivo, que dentro de las limitaciones que enfrentan para compatibilizar sus distintas metas, los bancos centrales de los países en desarrollo deben tener al menos tres objetivos: inflación, actividad económica y tipo de cambio $^{15}$. A ellos se agregan el de estabilidad financiera, en la medida en que dicha estabilidad está estrechamente ligada a la macroeconómica. Esto no significa, por supuesto, que la inflación sea un objetivo secundario o contingente con respecto al logro de otros; en economías con tradiciones inflacionarias como las latinoamericanas, debe ser sin duda un objetivo primario.

Una lectura alternativa del "trilema" indica obviamente que lo que debe ceder es la libertad al movimiento de capitales. Incluso más, la necesaria multiplicidad de objetivos que se deduce del análisis precedente, implica también que las autoridades deben contar con más instrumentos de política para poder alcanzarlos, condición que se acrecienta cuando la efectividad de cada instrumento específico es limitada ${ }^{16}$. Aquí subyace uno de los problemas fundamentales del manejo macroeconómico en economías abiertas: el costo de renunciar a instrumentos de política es alto en economías donde existe un predominio macroeconómico de la balanza de pagos. De hecho, en el pasado las economías latinoamericanas contaban con un sinnúmero de instrumentos, vinculados tanto a la política comercial como al control de capitales y de cambios, que se podían usar como instrumentos complementarios para mitigar las perturbaciones de origen externo. La renuncia a estos instrumentos tendió, por lo tanto, a descargar cada vez

\footnotetext{
${ }^{14}$ Nótese que este marco analítico supone, además, que la demanda es sensible a la tasa de interés, y que la tasa de interés que maneja el banco central tiene un efecto en las tasas que es relevante respecto de las decisiones de consumo e inversión. Ambos supuestos pueden también ser inapropiados en los países en desarrollo y por cierto lo son en economías con sistemas financieros no desarrollados plenamente.

${ }^{15}$ Es interesante resaltar que la ley de la Reserva Federal de los Estados Unidos le otorga objetivos múltiples. El de la tasa de cambio no existe, pero se agrega otro: el mantenimiento de tasas de interés de largo plazo moderadas. Es más, el de actividad económica se define como "empleo máximo" e incluso se formula en la ley antes que la estabilidad de precios.

${ }^{16}$ Este es el mensaje central que subyace en uno de los ensayos conocidos de Stiglitz (1998).
} 
más el manejo del ciclo externo en el tipo de cambio, que no es necesariamente el instrumento anticíclico más apropiado, según se ha visto. Si los instrumentos del pasado se consideran inadecuados para las economías latinoamericanas de hoy, será una tarea esencial de las autoridades crear otros nuevos.

Ante estos dilemas, las autoridades económicas del mundo en desarrollo han llegado pragmáticamente a la conclusión no solo de que los regímenes extremos son contraproducentes, sino que es necesario contar con otros instrumentos para retomar la autonomía tanto monetaria como cambiaria. Los dos instrumentos preferidos son el manejo activo de las reservas internacionales y el retorno a la regulación de los flujos de capital. Ambos se han venido utilizando con propósitos claramente anticíclicos y dan cuenta de que la tendencia en el manejo del tipo de cambio en el mundo en desarrollo ha sido hacia regímenes cambiarios "intermedios", de flexibilidad "administrada" — y en muchos casos, como en Asia o en el Perú, altamente administrada. Una forma de verlo es que optan por puntos en el interior del triángulo del "trilema". A dichos instrumentos se ha venido agregando un tercero: el uso de los instrumentos de regulación prudencial con propósitos anticíclicos. Estos últimos, en conjunto con la regulación de los flujos de capital, son los que se han cobijado bajo el techo de las regulaciones macroprudenciales. En algunos casos se incluyen también bajo este concepto instrumentos tradicionales de manejo monetario, muy especialmente el manejo activo de los encajes a los depósitos, una práctica que ya había retornado en varios países latinoamericanos durante el auge de 2003-2008 y que se utilizó en el sentido contrario, como instrumento de expansión, durante la crisis ${ }^{17}$.

La ventaja fundamental de un manejo activo de las reservas internacionales es que permite controlar simultáneamente el tipo de cambio y el tipo de interés incluso si hay movilidad de capitales, obviamente dentro de ciertos límites. Este es un punto que ha demostrado Frenkel (2007). Durante los auges, ello obviamente exige la acumulación esterilizada de reservas internacionales. Como lo señala la experiencia del mundo en desarrollo durante la reciente crisis, la disponibilidad de reservas amplía el margen para adoptar medidas monetarias expansivas durante las crisis a fin de hacer frente a la contracción de la demanda agregada. El manejo activo de las reservas permite, por lo tanto, mitigar el impacto

\footnotetext{
17 Así lo hace, por ejemplo, el FMI (2010, cap. 3), pero es mejor diferenciar claramente entre ambos.
}

de los flujos de capital en el tipo de cambio durante los auges, al tiempo que actúa como un mecanismo de prevención de crisis (auto-aseguramiento). El alto nivel de reservas permite, en consecuencia, la estabilidad de los regímenes cambiarios intermedios. Esta política no está exenta de costos, sobre todo porque la acumulación esterilizada de reservas es costosa: a nivel nacional, el rendimiento de los activos de reservas es inferior al de los capitales que ingresan al país durante los auges; y desde el punto de vista del banco central, el costo de los instrumentos de esterilización es generalmente superior al rendimiento de las reservas (aunque aquí pueden haber a lo largo del tiempo ganancias de capital vinculadas al manejo de las reservas que compensan dichos costos).

Estos costos son precisamente los que justifican el segundo instrumento que ha retornado, aunque en menor escala: la regulación de los flujos de capital, especialmente para tratar de reducir la entrada de capitales volátiles durante los auges. El término "regulaciones" es preferible al de "control", ya que en la práctica se actúa de manera similar a otras regulaciones financieras. Más aún, en la medida en que evitan la entrada de capitales volátiles tienen efectos prudenciales, por lo que pueden denominarse correctamente como regulaciones prudenciales a los flujos de capital. Sus efectos son de dos tipos: mejoran la estructura de los pasivos externos, haciéndola menos volátil, y amplían el margen para adoptar políticas macroeconómicas anticíclicas y, en este sentido, al igual que el manejo activo de las reservas internacionales, amplían la autonomía monetaria y cambiaria. Sin embargo, dichos efectos tienden a ser limitados y temporales, pero ello no implica que no deban ser utilizados, sino establecidos en la magnitud necesaria para que sean efectivos y ajustados dinámicamente a fin de compensar la tendencia de los mercados financieros a eludirlos -mecanismos que, en cualquier caso, son costos y permiten por ello algún grado de efectividad de las normas ${ }^{18}$. Una manera interesante de ampliar sus efectos e integrarlos más claramente con otros instrumentos de regulación es transformar los tradicionales encajes a la entrada de capitales, utilizados en el pasado en Chile y Colombia, en encajes a los pasivos en moneda extranjera, tanto del sector financiero como de agentes no financieros. De hecho, otros instrumentos de regulación monetaria y financiera actúan sobre los acervos y no sobre los flujos.

\footnotetext{
18 Para una revisión de la literatura correspondiente, véanse Ocampo (2008); Ostry y otros (2010).
} 
A la utilización de estos instrumentos con propósitos anticíclicos puede agregarse el uso, con el mismo propósito, de la regulación financiera interna de los países. Esto es, precisamente, lo que han sugerido el BPI y la CEPAL desde hace más de un decenio y que España innovó en la práctica a partir del año $2000^{19}$. La crisis actual empujó el debate hacia el uso activo de estos instrumentos. La modalidad que adoptó el Comité de Basilea de Supervisión Bancaria en 2010 se inclinó al uso de los requisitos de capital con propósitos anticíclicos. Pero a estos se podría agregar el empleo de las provisiones para deudas de dudoso recaudo (el sistema español) o los requisitos de liquidez con igual propósito, así como un conjunto más amplio de medidas ya mencionadas en una sección anterior, especialmente aquellas tendientes a manejar el efecto procíclico de los precios de los activos. Entre ellas, cabe subrayar la necesidad de prevenir los descalces de moneda en las estructuras de los balances, que generan riesgos notorios en los países en desarrollo y son responsables de uno de los principales efectos procíclicos de las fluctuaciones del tipo de cambio.

A estos dos tipos de regulaciones anticíclicas, orientadas al manejo de los ciclos de capital o a las actividades financieras internas, pueden agregarse otras. Una que estuvo muy en boga desde los años de auge de 2003-2008 es la mejora en la estructura de los pasivos del sector público. Un tipo de instrumento que no se ha utilizado es el tributario: por ejemplo, normas tributarias que desincentiven el uso de pasivos externos, permitiendo una menor deducción fiscal de los costos financieros vinculados a dichos pasivos, como lo sugirieron hace una década Stiglitz y Bhattacharya (2000).

La literatura empírica reciente se inclina abrumadoramente en favor de estas tesis. En ella se muestra, en particular, que la menor vulnerabilidad externa fue el elemento decisivo en el buen desempeño relativo de las economías en desarrollo durante la crisis reciente. Dependiendo de los estudios correspondientes, la menor vulnerabilidad externa se relaciona con una mezcla de cinco factores interrelacionados: i) menores déficits en cuenta corriente; ii) tasas de cambio competitivas; iii) alto nivel de reservas internacionales; iv) bajo monto de pasivos externos de corto plazo, y v) regulaciones de los flujos de capital ${ }^{20}$. Este énfasis en la vulnerabilidad externa resalta la validez de la visión según la cual el

\footnotetext{
${ }^{19}$ Véase una revisión de los antecedentes y el debate correspondiente en Griffith-Jones y Ocampo (2010) y de la experiencia española en Saurina (2009).

${ }^{20}$ Véanse, entre muchos otros, Frankel y Saravelos (2010); Frenkel (2010); Llaudes, Salman y Chivakul (2010); Ostry y otros (2010).
}

predominio macroeconómico de la balanza de pagos es el tema esencial que debe ser manejado en las economías en desarrollo.

Aquí subyace la principal fuente de "solidez macroeconómica" de los países en desarrollo en el último decenio, más que en la solidez fiscal (donde hay grandes excepciones como, por ejemplo, la India) o la difusión de bancos centrales independientes que adoptan como marco para su política objetivos de inflación y tasas de cambio flexibles. En la práctica, como se ha visto, lo que se ha extendido es la flexibilidad administrada de los tipos de cambio e implícitamente manejos monetarios y cambiarios en que se combina el objetivo de inflación con el nivel de actividad económica y el tipo de cambio. Esa flexibilidad administrada y su mezcla variable con el manejo activo de reservas internacionales y macroprudencial, incluidas las regulaciones de los flujos de capital, es lo que ha permitido reducir la vulnerabilidad externa y aumentar la autonomía monetaria y cambiaria.

En este sentido, la ganancia principal de América Latina durante el auge del período 2003-2008 fue la reducción de la deuda externa y, especialmente, de la deuda externa neta de reservas internacionales como se aprecia en el gráfico 4, como resultado tanto de la disminución de la deuda como de la acumulación de reservas. El desarrollo de un mercado interno de bonos de deuda pública fue parte importante de este proceso, en la medida en que permitió aminorar la dependencia tradicional del financiamiento externo del sector público. La fuente de mejoría no fueron los menores desequilibrios fiscales como tales, que en realidad datan desde hace dos décadas (véase el gráfico 3), ni la tendencia al uso de políticas fiscales anticíclicas, que como hemos visto siguen siendo la excepción más que la regla. Tampoco lo fue la moderación en el ritmo de crecimiento de la demanda agregada, que más bien aumentó a ritmos elevados. Esto se corrobora en el gráfico 5, donde se observa que la cuenta corriente mejoró en promedio, pero más como producto del auge de los términos de intercambio que de la austeridad en el gasto. De hecho, ajustado por los términos de intercambio, hubo un marcado deterioro de la cuenta corriente, lo que indica que América Latina tendió, en promedio, a gastar el auge de los precios de productos básicos; esto fue, además, la regla, de la que solo se escapa un puñado de países (Ocampo, 2009). En cualquier caso, los resultados globales relativamente balanceados de la cuenta corriente, facilitados por el auge de precios de productos básicos, ayudaron a mejorar las hojas de balance externo, que a su vez ampliaron los márgenes de autonomía macroeconómica. 
GRÁFICO 4 América Latina: deuda externa como porcentaje del PIB, 1998-2010 (En dólares de 2000)

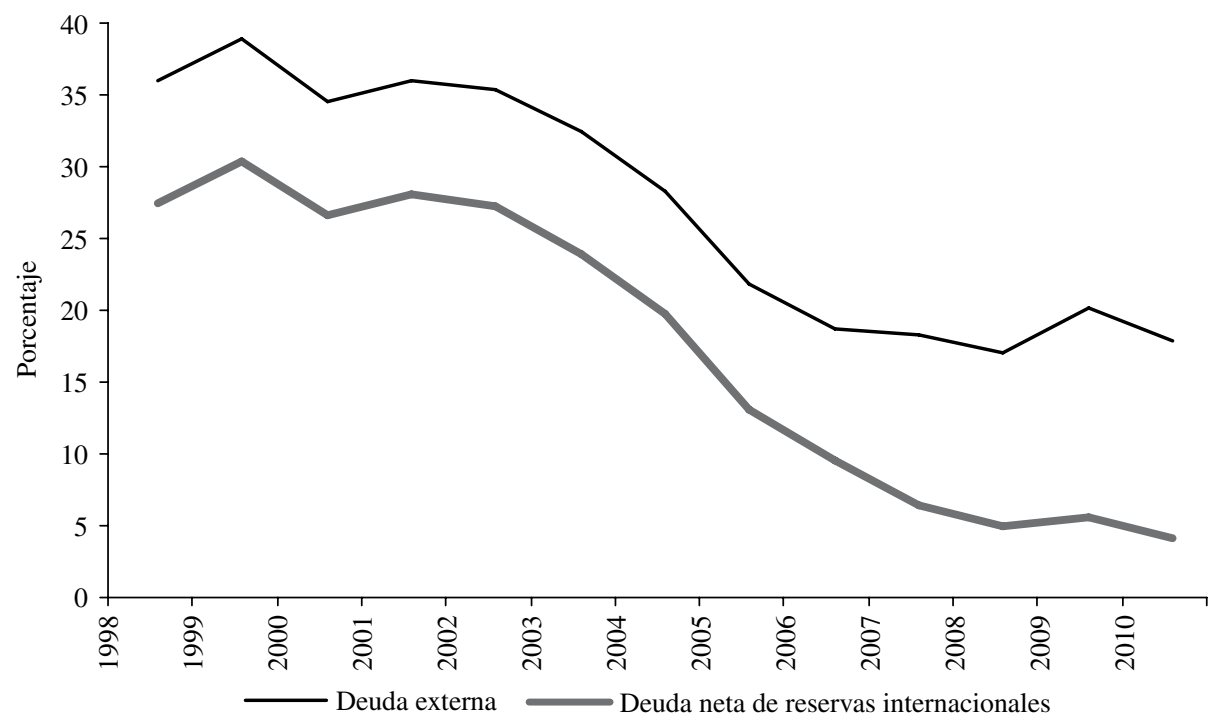

Fuente: estimaciones del autor sobre la base de datos de la Comisión Económica para América Latina y el Caribe (CEPAL). PIB: producto interno bruto.

GRÁFICO 5 América Latina: balance de la cuenta corriente ajustado por términos de intercambio, 1997-2010 (En porcentajes)

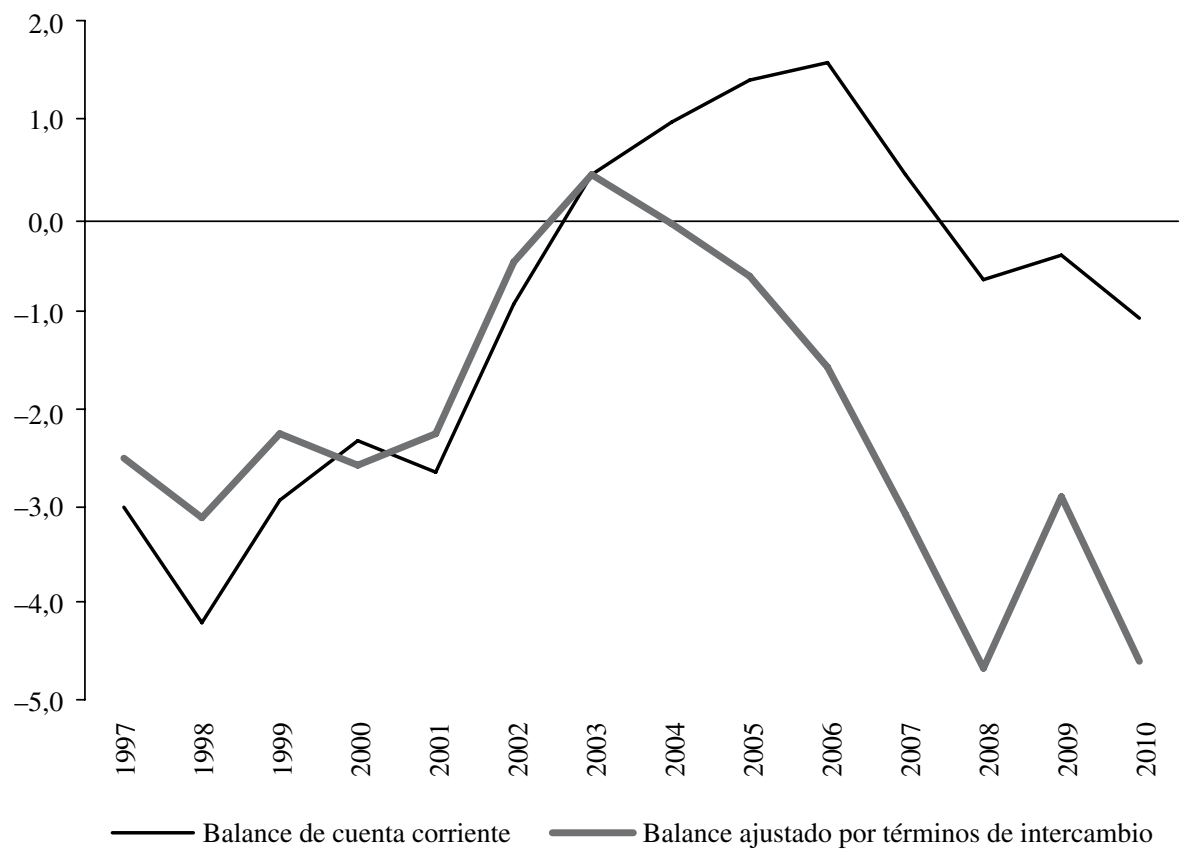

Fuente: estimaciones del autor sobre la base de datos de la Comisión Económica para América Latina y el Caribe (CEPAL). 


\section{IV}

\section{Crecimiento económico y cambio estructural}

\section{Patrones de especialización y crecimiento económico}

El crecimiento económico va siempre acompañado de cambios en las estructuras productivas: en la composición del PIB y del empleo, y en los patrones de especialización internacional. Además, en los países en desarrollo, los rápidos incrementos en la productividad se vinculan siempre a la transferencia de mano de obra de sectores de baja productividad a otros de alta productividad, como lo señaló la teoría clásica del desarrollo y lo ha formulado contemporáneamente Ros (2000). Sin embargo, en la mayor parte de los análisis tradicionales se hace abstracción de esta vinculación entre crecimiento económico y estructura productiva, lo que indica que en ellos se ve a dicha estructura simplemente como un subproducto del crecimiento. La esencia de las visiones "estructuralistas", incluidas las que ha encarnado históricamente la CEPAL, es la percepción de que estos cambios no son un mero subproducto, ni tampoco neutros en términos de sus efectos: ellos son el motor mismo del crecimiento económico. En este sentido, el desarrollo no es otra cosa que la capacidad de una economía de generar nuevas actividades productivas dinámicas (Ocampo, 2005). Alternativamente, la ausencia de crecimiento está ligada a la interrupción del proceso de cambio estructural.

En los países industrializados, el motor de este proceso es el cambio tecnológico. Dado que este cambio es una actividad altamente concentrada a nivel mundial, genera un patrón centro-periferia, como bien lo señalara Prebisch. En los países en desarrollo, el motor del crecimiento es la capacidad para absorber, con un rezago, dicho cambio tecnológico y las actividades que van madurando tecnológicamente y se transfieren en forma gradual a la periferia, o de responder a las demandas de productos básicos que produce la expansión en el centro. La transferencia de tecnologías y actividades productivas no es pasiva. Ella involucra un proceso activo de atracción de las industrias o, con la desintegración de las cadenas de valor, actividades que se van desplazando desde el centro, pero que desde el punto de vista de la periferia son nuevas actividades productivas, así como un proceso igualmente activo de aprendizaje tecnológico que también puede generar innovaciones secundarias (Katz, 1987). Si la reducción de la brecha tecnológica es exitosa, los rezagos tenderán a decrecer e incluso los países en desarrollo podrán convertirse en fuentes secundarias de tecnología.

Este énfasis en la transformación de las estructuras productivas no es antagónico con alcanzar altas tasas de inversión. Las economías que crecen rápidamente tienen también tasas de inversión elevadas, pero esta relación es mucho menos sistemática que la que existe entre crecimiento económico y transformación estructural (Ocampo, Rada y Taylor, 2009, cap. 3). Una manera de entender la preferencia que aquí se hace es que las tasas de inversión son más efecto que causa de una transformación estructural dinámica. Por eso, en este ensayo se pone énfasis en la transformación estructural más que en la inversión. Sin embargo, con esto no se ignora que pueden haber otros determinantes de la formación de capital que aquí no se analizan, sobre todo los relacionados con los mecanismos de financiamiento.

Las razones por las que el crecimiento económico y los cambios en las estructuras productivas están interrelacionados son diversas. La primera explicación, y la que tiene mayor tradición en el pensamiento sobre desarrollo económico, es que distintas ramas productivas generan oportunidades muy diferentes de generación y transmisión del progreso técnico y, por ende, de aumentar la productividad de la economía. En la defensa clásica de la industrialización se argumentaba precisamente que las actividades industriales eran un mejor canal para transferir tecnología e inducir otras innovaciones. Algunas actividades primarias, en la agricultura y la minería, también pueden experimentar incrementos acentuados de la productividad, pero han sido menos efectivas para transmitir esos aumentos a otros sectores productivos.

Ello conduce a la segunda explicación, que tiene que ver con los eslabonamientos productivos de distintos sectores. Los más tradicionales, que fueron el centro de atención de Hirschman (1958), se relacionan con la demanda que una nueva actividad genera en otras (encadenamientos hacia atrás), así como con las posibilidades que ofrece para desarrollar otras actividades (encadenamientos hacia delante). Lo que es esencial en este caso como en el de transmisión del progreso técnico es que los efectos se localicen en un mismo territorio y no se filtren hacia el resto del mundo, como tiende a ocurrir en una economía mundial cada vez más integrada. 
Un tipo de encadenamientos de más reciente formulación se vincula a lo que Hidalgo y otros (2007) denominan el "espacio de productos" (product space). La interpretación que esos autores hacen de este concepto es que los factores e insumos que se utilizan en una rama productiva son siempre específicos: instalaciones productivas particulares, trabajadores con cierto tipo de capacidades, insumos intermedios específicos, entre otros. Por lo tanto, no pueden ser utilizados en otras actividades directamente, sino con menores niveles de productividad. Sin embargo, pueden ser empleados o adaptados a actividades que se encuentran más cercanas en el "espacio de productos". En este sentido, la capacidad de innovar y diversificar la actividad productiva dependerá de qué actividades se encuentran más "cercanas". De esta manera, la "densidad" de actividades productivas cercanas (el símil que los autores utilizan es el de las partes más o menos densas de un bosque) genera oportunidades muy diferentes de diversificación productiva.

Estos dos fenómenos, que en un sentido general podemos denominar "innovación" y "complementariedades", son los elementos esenciales de toda política de desarrollo productivo. La interrelación entre unos y otros constituye la fuente de las principales externalidades y, por ende, de las fallas de mercado: las fallas de coordinación y los derrames o difusión de la información (de los que forman parte los tecnológicos). En el primer caso, el problema esencial es la interrelación en las decisiones de inversión de distintos agentes económicos, por lo que en ausencia de coordinación entre ellos (que el mercado no garantiza), las inversiones pueden no darse o darse en cantidades "subóptimas". El segundo caso se relaciona con el hecho de que la "nueva información" es costosa para el agente que la debe adquirir, pero los beneficios pueden favorecer a otros agentes. De este modo, la inversión en adquirir dicha información puede resultar nuevamente subóptima.

La evidencia de una vinculación entre los patrones de especialización y el ritmo de crecimiento es amplia. En la literatura reciente, el ensayo de Hausmann, Hwang y Rodrik (2007) es quizás el intento más importante de mostrar que la "calidad" o contenido tecnológico de las exportaciones es un determinante fundamental del crecimiento de los países. Los autores estiman dicho contenido como el "nivel de ingreso" incorporado en las exportaciones (el valor de las exportaciones ponderado por el nivel de ingreso de los países que típicamente exportan los mismos productos).

Ocampo, Rada y Taylor (2009, cap. 4) proporcionan un ejercicio más simple en que se estima la relación entre el crecimiento económico y el patrón dominante de desarrollo exportador de acuerdo con el contenido tecnológico, siguiendo en este último caso las categorías propuestas por Sanjaya Lall. Este ejercicio indica que los países especializados en exportaciones con alto contenido tecnológico tienden a crecer más rápidamente, seguidos por aquellos en que predominan exportaciones de media y baja tecnología, en tanto que los países con estructuras exportadoras basadas en recursos naturales tienden a crecer más lentamente. Esta propensión no es tan notoria durante los períodos de altos precios de productos básicos, lo que señala que una de las causas de la superioridad a largo plazo de crecimientos basados tanto en industrias de alta como de baja tecnología, es que dependen menos de coyunturas excepcionales de precios y ofrecen, en ese sentido, procesos de desarrollo más estables. Curiosamente, las exportaciones de tecnología media, que están fuertemente dominadas por productos químicos y siderúrgicos estandarizados (commodities industriales) no cuentan con esta ventaja.

Vale la pena resaltar que la desintegración de las cadenas de valor puede generar un divorcio entre el contenido tecnológico de los productos exportados y las tareas productivas, especialmente en los procesos de maquila. En estos casos, y en industrias exportadoras con altos contenidos importados, las complementariedades tienden también a ser muy limitadas. Por ello, muchas actividades manufactureras de exportación pueden carecer de las virtudes que se les adscribe en la literatura económica.

Los problemas que plantea la especialización en recursos naturales tienen varias dimensiones que conviene destacar y que han sido exploradas en la controversia sobre la "maldición de los recursos naturales" 21. Este tipo de especialización plantea dos problemas diferentes, que han sido muy bien identificados por Agosin (2007): los efectos propiamente estructurales (es decir, productivo-tecnológicos) de dicho patrón de especialización y los problemas de vulnerabilidad macroeconómica (que denomina "efectos portafolio"). En términos del análisis de Hidalgo y otros (2007), el primer problema se relaciona con el hecho de que los países ricos en recursos naturales (incluidos los petroleros) se

\footnotetext{
${ }^{21}$ El trabajo de Sachs y Warner (1995) es el intento más conocido de corroborar econométricamente los efectos adversos en el crecimiento de un patrón de especialización basado en recursos naturales. Lederman y Maloney (2007) proporcionan una visión contraria. Fuera de los problemas económicos que se discuten en el texto, dicha "maldición" puede estar también vinculada a factores de economía política, en particular los comportamientos "rentísticos" que genera.
} 
encuentran en partes poco densas del espacio de productos y, por ello, sus oportunidades de diversificación productiva son limitadas. El segundo tiene que ver con la mayor susceptibilidad a crisis originadas en el sector externo en países especializados en recursos naturales, que se relacionan con estructuras exportadoras menos diversificadas y fuertes fluctuaciones de los términos de intercambio, uno de cuyos efectos es la fuerte propensión a políticas procíclicas y a las agudas crisis que generan $^{22}$. La "enfermedad holandesa" conecta ambos problemas: en este caso, el problema esencial es que los auges de los precios de productos básicos provocan una tendencia a la revaluación que puede tener efectos permanentes en la estructura productiva que resultan costosos cuando los precios se reducen nuevamente ${ }^{23}$. Más adelante se abordan los problemas que genera el manejo cambiario.

En oposición a estas visiones, existe una literatura en que se postula que los encadenamientos hacia delante y hacia atrás de la producción primaria pueden utilizarse como palanca para la diversificación productiva. Suecia y Finlandia son dos de los casos más exitosos de procesos de diversificación productiva de esta naturaleza (Blomström y Kokko, 2007), así como Australia y Nueva Zelandia (CEPAL, 2006, cap. V). Existen, además, nichos específicos de productos básicos que han mostrado dinamismo en los mercados internacionales y que tienen altos requisitos tecnológicos en cuanto a estándares de

22 Sobre este tema, véase también Manzano y Rigobón (2007).

${ }^{23}$ Hay muchas formulaciones de este problema, pero una de las más acertadas es la de Krugman (1987). calidad, procesamiento, mantenimiento o transporte de los productos, algunos de los cuales enfrentan además mercados dinámicos (Akyüz, 2003, cap. 1; CEPAL, 2008a, caps. III y V).

Por ese motivo, y más allá de los problemas específicos que plantea la especialización en recursos naturales, el problema esencial de América Latina es el escaso contenido tecnológico de sus actividades productivas y los bajos niveles de investigación y desarrollo, no solo si se compara con las naciones más exitosas de Asia oriental, sino también con los países industrializados cuyas exportaciones son intensivas en recursos naturales. En el cuadro 2, tomado de Cimoli y Porcile (2011), así como en el ensayo más amplio de CEPAL (2007) sobre este tema, se corrobora esta apreciación.

En muchos trabajos se ha señalado, en efecto, que una de las diferencias más importantes entre las experiencias exitosas de Asia oriental y de América Latina es que en la primera se hizo un nítido tránsito hacia la capacidad de generar conocimiento, un área donde América Latina muestra todavía muchos atrasos (CEPAL, 2008a, cap. III; Cimoli y Porcile, 2011; Palma, 2009 y 2011). Hausmann (2011) ha mostrado asimismo que el menor crecimiento de largo plazo de la región se vincula tanto a la menor calidad de su canasta exportadora como a su localización, en general, en lugares poco densos del espacio de productos. Por el contrario, los países industrializados se encuentran, en general, en partes densas de dicho espacio y las economías dinámicas de Asia oriental se han ido moviendo hacia allá.

La principal conclusión es que, más allá de la capacidad diferencial de distintas ramas productivas de ser un camino para incrementar la productividad,

CUADRO 2

Especialización, estructura productiva y crecimiento

\begin{tabular}{lccccrrrr}
\hline & PR1 & PR2 & IK & IA & Porcentaje RN & I+D & Patentes & PIB pc \\
\hline América Latina & 0,30 & 0,23 & 0,78 & 0,44 & 70 & 0,40 & 0,5 & 1,6 \\
Países desarrollados basados en recursos naturales & 0,70 & 0,72 & 0,33 & 1,32 & 59 & 1,89 & 65,4 & 2,3 \\
Países emergentes de Asia & 0,80 & 0,99 & 0,39 & 2,33 & 30 & 1,21 & 30,5 & 4,8 \\
Economías maduras & 0,88 & 0,97 & 0,16 & 1,80 & 24 & 2,43 & 132,6 & 2,0 \\
\hline
\end{tabular}

Fuente: Mario Cimoli y Gabriel Porcile, "Learning, technological capabilities and structural dynamics", The Oxford Handbook of Latin American Economics, José Antonio Ocampo y Jaime Ros (eds.), Nueva York, Oxford University Press, 2011.

Nota: Economías maduras: Francia, Italia, Reino Unido, Estados Unidos, Japón y Suecia.

Países desarrollados basados en recursos naturales (RN): con $40 \%$ o más de las exportaciones basadas en dichos recursos.

PR1: participación de industrias de ingeniería en el valor agregado de la industria (cociente respecto de los Estados Unidos 1982-2002).

PR2: participación de industrias de ingeniería en el valor agregado de la industria (cociente respecto de los Estados Unidos 2002-2007).

Patentes: patentes acumuladas por millón de habitantes (1996-2007).

PIB pc: crecimiento del PIB per cápita (1970-2008).

IA: índice de adaptabilidad (1985-2000).

IK: índice de Krugman (Estados Unidos).

I+D: inversión en investigación y desarrollo como porcentaje del PIB (1996-2007). 
la clave del crecimiento dinámico es la sincronía entre desarrollo exportador, encadenamientos productivos y acumulación de capacidades tecnológicas.

\section{Políticas de desarrollo productivo en economías abiertas}

La relación entre estructura productiva y crecimiento económico conlleva, como es obvio, implicaciones profundas de política económica. En la medida en que el desarrollo esté estrechamente ligado a los cambios en las estructuras productivas, una tarea esencial de la política económica será garantizar la capacidad de las economías de lograr una transformación productiva dinámica, por medio de políticas activas de desarrollo productivo. Este concepto es preferible al de "políticas industriales", porque no presume necesariamente, como en el pasado, que ellas se vinculan específicamente con la producción manufacturera, sino que pueden ponerse en marcha en sectores intensivos en recursos naturales o de servicios. Una de las virtudes de esta formulación es que ofrece oportunidades de desarrollo a un conjunto amplio de países de la región, muchos de los cuales no pueden aspirar a la exportación de productos de alta tecnología.

En economías abiertas como las latinoamericanas de hoy, dicha tarea está íntimamente ligada a la capacidad de desarrollar estructuras exportadoras con contenidos tecnológicos cada vez mayores. Sin embargo, el mercado interno no puede dejarse de lado, ya que sigue cumpliendo un papel muy importante en los procesos de crecimiento. Para la mayoría de los países de la región, los procesos de integración deberían jugar el papel de "mercado interno ampliado", pero para ello hay que superar los múltiples obstáculos que enfrentan esos procesos, tanto de carácter económico (su marcada susceptibilidad al ciclo económico) como político. También hay que prestar particular atención a los eslabonamientos productivos de las actividades exportadoras, que representan lo que se puede denominar el "mercado interno" generado por la actividad exportadora. Estos encadenamientos son parte de las complementariedades que genera la actividad exportadora. Asimismo, se puede argumentar que la competitividad de un sector exportador, que lo hace menos susceptible de relocalización, reside precisamente en las actividades complementarias productoras de insumos o servicios a nivel local, sobre todo los no comercializables internacionalmente (o solo imperfectamente comercializables). Estas complementariedades son, para utilizar la terminología de la CEPAL (1990), las fuentes de competitividad sistémica.
El debate sobre la naturaleza de las políticas de desarrollo productivo plantea varios interrogantes, que solo se pueden bosquejar en este artículo. El primer interrogante se refiere a cuál debe ser el foco de la política. En este sentido, en la literatura se propende a resaltar que el énfasis debe recaer en aquellas actividades innovadoras que generan externalidades (véanse, al respecto, Ocampo, 2005; Rodrik, 2007a, cap. 4; Cimoli, Dosi y Stiglitz, 2009). Esta definición pone énfasis en un tema que resulta esencial, como hemos visto, en un mundo caracterizado por la ruptura de las cadenas de valor. A su vez, el concepto de innovación no debe entenderse exclusivamente como innovación tecnológica, sino - en un sentido más amplio_ c como "nueva actividad". Esto implica que, aparte de lo tecnológico (nuevos procesos productivos y nuevos productos), incluye lo comercial (por ejemplo, nuevas maneras de comercializar y la conquista de nuevos mercados); nuevas formas de estructurar una empresa o una industria y la explotación de nuevas fuentes de materias primas. Este es el concepto que hemos defendido en un ensayo anterior (Ocampo, 2005), pero es también el que utilizan Australia y Nueva Zelandia en su política de innovación (CEPAL, 2006, cap. V). La generación de externalidades es clave, puesto que implica que los beneficios de la innovación no son apropiados exclusivamente por la empresa que la realiza, y se pueden dar nuevamente tanto en el terreno tecnológico como comercial ${ }^{24}$.

A largo plazo, el objetivo esencial de toda política de desarrollo productivo es, en cualquier caso, la acumulación de capacidades tecnológicas. Este objetivo plantea un segundo grupo de interrogantes. Algunos de ellos se refieren a la coexistencia de sectores productivos de alta y baja productividad, y a la manera como se promueve la difusión de tecnología. Otros tienen que ver con la relación entre la acumulación de capacidades productivas y de capacidades tecnológicas. La adquisición de las primeras siempre exige aprender a utilizar una tecnología determinada, en tanto que las segundas involucran un proceso más activo, que va desde la adaptación de tecnología y la introducción de pequeñas innovaciones o modificación del diseño de productos, hasta la capacidad de generar nueva tecnología y nuevos productos.

En las primeras etapas del desarrollo, e incluso en ciertas industrias hoy en día, el aprendizaje tecnológico es un subproducto del desarrollo de un nuevo sector

\footnotetext{
24 Se reconoce a un país o una región como fuente confiable de abastecimiento de un producto y la generación de canales de comercialización que benefician a otros productores.
} 
productivo. En tal caso, la tecnología juega un papel importante pero pasivo. Así, el centro de atención de la política debe ser la promoción del sector más que una estrategia explícita de carácter tecnológico. De alguna manera, esto fue lo que se logró durante la etapa de industrialización dirigida por el Estado, en la que el desarrollo tecnológico fue un subproducto más que el resultado de una política tecnológica como tal, que en general estuvo ausente en América Latina con notables excepciones (entre ellas, en la agricultura). $\mathrm{La}$ sustitución de dicha estrategia por una de liberalización comercial promovió, sin duda, incentivos para adoptar la mejor tecnología a fin de poder competir y obligó a racionalizar los procesos productivos. Sin embargo, con ello se privilegió la importación de tecnología por sobre los esfuerzos de adaptar y generar tecnología, incluso desmantelando en algunos casos mecanismos tecnológicos que se habían desarrollado en el pasado. En términos de su capacidad para inducir crecimiento económico, estos procesos demostraron ser menos eficaces en América Latina que la estrategia precedente.

Por lo tanto, es crucial la identificación de cuándo o en qué sectores el foco de atención debe ser la actividad productiva o el desarrollo de un sistema de innovación. $\mathrm{Al}$ respecto no existe una respuesta única. En algunos casos la innovación tecnológica local es fundamental para la competitividad. Esto ocurre en sectores de alta tecnología que existen en la región (la industria aeronáutica brasileña, por ejemplo), pero también puede representar un papel clave en sectores intensivos en recursos naturales (el papel de los institutos nacionales de investigación en el desarrollo de los complejos agroalimentarios). En cualquier caso, la adaptación y creación de conocimiento constituyen siempre "industrias incipientes" y, por ello, deben ser objeto preferencial de toda política de desarrollo productivo.

Cuando el papel activo lo cumple el desarrollo productivo puede no ser evidente cuál es la "actividad innovadora" que se debe promover $y$, debido a esto, la promoción de la innovación puede identificarse con el fomento al desarrollo del propio sector. En este contexto, decir que toda estrategia selectiva es incorrecta porque implica "elegir ganadores" significa ignorar las características que son intrínsecas a las políticas de desarrollo productivo. Lo primero que se ignora es que el proceso es de aprendizaje, y se refiere a qué es lo que vale la pena promover y, más aún, a cómo hacerlo. Muchos detalles deben aprenderse en el camino e involucrarán errores. En este sentido, el tipo de elección no es muy diferente al de cualquier empresa privada que quiere expandirse hacia nuevas líneas productivas, lo que implica una apuesta estratégica sobre la base de las capacidades acumuladas por la empresa y, asimismo, la posibilidad de cometer errores. Por otra parte, el proceso que pone en marcha la política consiste en crear las condiciones para que se tenga éxito y, por ende, más que elegir ganadores se trata realmente de construirlos. Se reconoce, además, una de las conclusiones básicas de la moderna teoría del comercio internacional: que en presencia de economías de escala, entre las que se destaca el proceso de aprendizaje, las ventajas comparativas son, en gran medida, creadas.

Ya sea el enfoque tecnológico o sectorial, los incentivos pueden ser de carácter horizontal o selectivo. Hay elementos esenciales de carácter horizontal que debe contener toda política de desarrollo productivo, especialmente mecanismos para fomentar la innovación y difusión de tecnología, mejorar los mecanismos de financiamiento de largo plazo y apoyar a las micro, pequeñas y medianas empresas. Sin embargo, hay argumentos poderosos en favor de estrategias selectivas, ya que las oportunidades de innovación no se dan en todo el espectro de la estructura productiva. Es más, en la preferencia genérica por esquemas horizontales se ignora que cuando estos involucran recursos fiscales escasos, siempre habrá que especificar dónde se asignan los recursos y eso implica selectividad de algún tipo. Por ese motivo, cualesquiera sean los instrumentos utilizados, la elección debe hacerse en el contexto de una estrategia de desarrollo productivo. Más aún, por motivos de transparencia es mejor que esta elección sea explícita y no meramente implícita.

Un tercer tipo de interrogantes se relaciona con las alianzas público-privadas, que son inherentes a toda política de desarrollo productivo. La necesidad de una alianza se deriva de los problemas de información que enfrentan los distintos agentes: mejor información sobre los procesos productivos y los mercados por parte del sector empresarial, pero mejor información sobre la economía en su conjunto, el manejo de las negociaciones internacionales $\mathrm{y}$, sobre todo, capacidad de coordinación de los distintos agentes por parte del Estado. No obstante, es esencial garantizar que los incentivos que otorga el Estado sirvan efectivamente a un propósito colectivo y no se transformen en meras rentas. El tema crucial es la forma de lograr una estrecha colaboración para garantizar la relevancia de las políticas, pero evitar al mismo tiempo su captura por parte de los agentes privados. Las soluciones son múltiples, como lo ilustran las diversas experiencias en este campo en el mundo entero (CEPAL, 2008a, cap. VI; Devlin y Moguillansky, 2010). La interacción público-privada debe visualizarse, 
al igual que la política de desarrollo productivo, como un proceso de aprendizaje mutuo.

El último tipo de interrogantes se relaciona con la temporalidad de los incentivos. La posibilidad de cometer errores implica, en primer término, que el sistema tiene que incluir claros mecanismos para reconocer cuándo se cometen y corregirlos. La contraprestación de todo incentivo debe ser, asimismo, un requisito de desempeño - es decir, un "mecanismo de control recíproco", para utilizar el término de Amsden (2001). Además, la naturaleza misma de los incentivos entraña que deben durar solo en la medida en que se cumplen sus requisitos básicos: que sean necesarios para que tenga lugar la innovación y que esta se difunda a otros agentes. Pero la naturaleza de las imperfecciones de información involucra que puede ser artificial definir plazos estrictos en el inicio de un proceso sobre el que no se dispone de toda la información. De hecho, la definición de plazos puede provocar que los incentivos terminen siendo insuficientes y, por ende, se acaben despilfarrando (es decir, aumente la probabilidad de "crear perdedores" en vez de ganadores, o de extender plazos que se anunciaron inicialmente como estrictos a costa de la credibilidad de las autoridades). Una vez más, lo que se necesita es el diseño de un proceso que permita identificar cuándo se va por el camino inadecuado, así como cuándo se puede confiar en que la innovación se ha consolidado.
Todo esto requiere invertir en el desarrollo de las instituciones encargadas de ejecutar estas políticas. Si algo se puede decir en este ámbito, es que la destrucción institucional durante el período de reformas de mercado fue amplia en América Latina. Por fortuna, se mantuvieron algunas instituciones del pasado que se han readecuado al nuevo contexto y, más recientemente, se ha iniciado una nueva ola de reconstrucción institucional. El caso más destacado es, sin duda, el de la estrategia de desarrollo productivo de Brasil.

\section{Interacción entre macroeconomía y desarrollo pro- ductivo y el papel crítico del tipo de cambio}

Una forma simple de visualizar el vínculo entre desarrollo productivo y condiciones macroeconómicas es por medio de la doble relación que existe entre crecimiento económico y aumento de la productividad, que se presenta en el gráfico 6 (véase Ocampo, 2005). La función de progreso técnico, TT, está determinada por las condiciones estructurales. La causalidad va en este caso del crecimiento de la producción al de la productividad: el primero induce un incremento de la productividad mediante la mayor inversión (mejor tecnología incorporada en los equipos), los procesos de aprendizaje y la reasignación de mano de obra de sectores de baja productividad a los de alta productividad.

GRAFICO 6

Relación entre el crecimiento del PIB y de la productividad

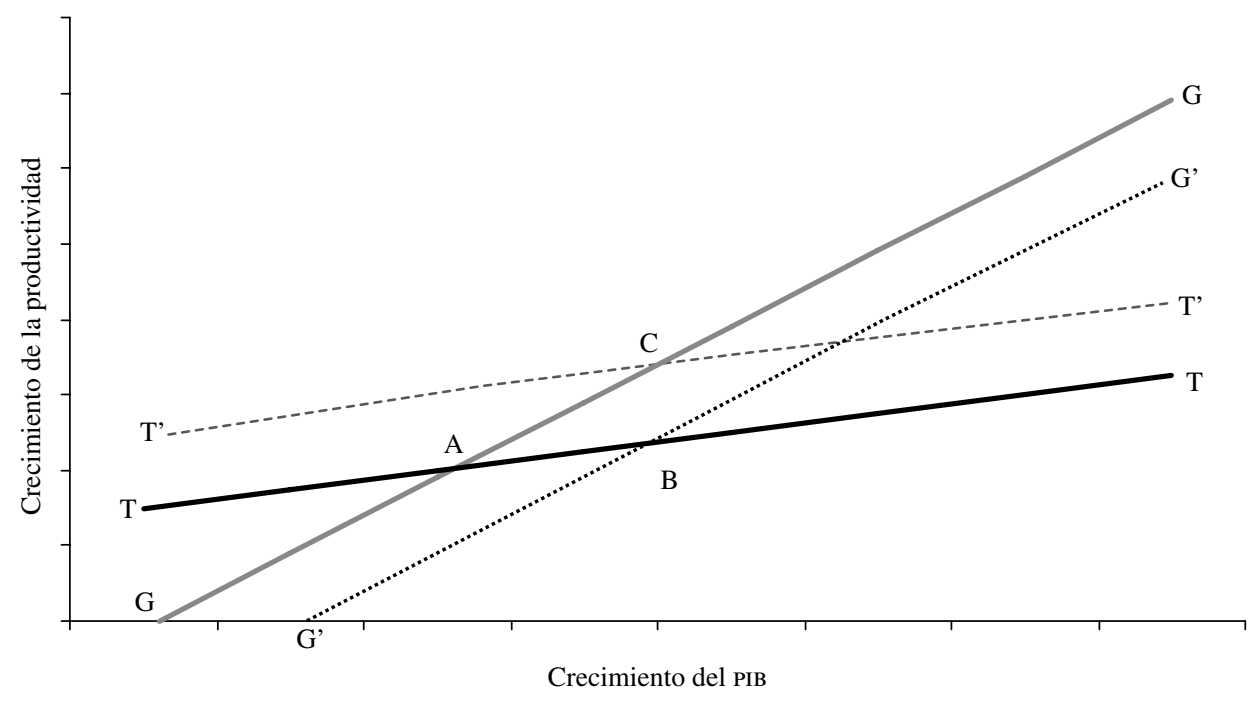

Fuente: elaboración del autor.

PIB: producto interno bruto. 
Por su parte, la relación de equilibrio macroeconómico, GG, representa alternativamente un equilibrio de demanda agregada $\mathrm{o}$, si existe una brecha externa, de equilibrio de la balanza de pagos. La relación es positiva en ambos casos, con una causalidad que va de los aumentos de productividad al crecimiento, pero opera por canales diferentes en uno y otro caso. Si el equilibrio es de demanda, el incremento de productividad induce aumentos de inversión, de los ingresos laborales (y del consumo) y mejora el balance externo. En el segundo caso, los acrecentamientos de productividad elevan las exportaciones o reducen las importaciones y por una $\mathrm{u}$ otra vía combaten la brecha externa.

El equilibrio se logra en el punto A. Si las condiciones macroeconómicas mejoran, la curva GG se desplaza a la derecha y genera un nuevo equilibrio (B) en el que hay simultáneamente más crecimiento y mayores ritmos de aumento de la productividad. El efecto puede operar por medio de una política macroeconómica expansiva que resulta sostenible, en especial porque induce mayores niveles de inversión y no genera barreras inflacionarias ni desequilibrios insostenibles de la balanza de pagos. Una política exitosa de desarrollo productivo desplaza, a su vez, la función TT hacia arriba, generando tanto más crecimiento económico como incrementos en la productividad (punto $\mathrm{C}$ en el gráfico 6).

Como lo resaltan Ocampo (2005) y Ocampo, Rada y Taylor (2009), esto implica que la relación entre incrementos en la productividad y en el crecimiento es de doble vía, al contrario de la tradicional forma de ver a la productividad como la causa y al crecimiento económico como el efecto ${ }^{25}$. En particular, un mal desempeño en materia de crecimiento tiende a aminorar los ritmos de aumentos de la productividad. Las causas pueden ser diversas: una crisis de balanza de pagos o un proceso de reestructuración productiva con muchos elementos de destrucción. La reducción de la productividad opera a través de los canales ya mencionados: menor inversión y aprendizaje, y una reasignación perversa de mano de obra hacia sectores informales. Un buen desempeño macroeconómico tiene el efecto contrario.

Aunque es posible utilizar este esquema conceptual para analizar muchos problemas, la atención se concentrará aquí en la tasa de cambio real, quizás la variable macroeconómica más crítica en economías abiertas. Esta variable establece, además, una conexión básica entre el

\footnotetext{
${ }^{25}$ El problema fundamental surge del supuesto de pleno empleo de recursos en los modelos de crecimiento tradicionales, en los que el efecto solo iría de la productividad al crecimiento.
}

análisis del crecimiento y el de las políticas anticíclicas, que se expuso en secciones anteriores.

La tasa de cambio tiene varias complejidades que conviene resaltar. La primera es que, dado su carácter macroeconómico, no puede generar los incentivos selectivos que se pueden lograr a través del régimen comercial y, por ello, sirve como sustituto parcial, pero no completo, de una política de desarrollo productivo. La segunda es que al mismo tiempo es el precio de un conjunto de activos financieros y uno de los determinantes del precio relativo de los bienes y servicios que se transan en el comercio internacional.

Esto último produce complejidades bien conocidas. Por ejemplo, una de las ideas fundamentales detrás del concepto del "sesgo anti-exportador" era que la protección conducía a una sobrevaluación del tipo de cambio, que afectaba a los incentivos para exportar. La expectativa ortodoxa era, por lo tanto, que la disminución en la protección provocaría una devaluación real que incentivaría el desarrollo exportador. Sin embargo, a partir de las experiencias de los países del Cono Sur en el decenio de 1970, sabemos que si la apertura va acompañada de un incremento en el ingreso de capitales, como resultado de su coincidencia con una apertura de la cuenta de capitales, no solo no se genera la devaluación real esperada, sino que incluso puede producirse el resultado opuesto: una revaluación real. De esta manera, se elimina el canal a través del cual la liberalización corrige el "sesgo anti-exportador" y se puede dar incluso un resultado paradójico: un proceso de crecimiento económico liderado por la demanda interna, no por las exportaciones. Este resultado ha sido común en América Latina (véase, entre muchos otros, Vos y otros, 2006, cap. 3).

La evidencia empírica indica que el tipo de cambio real es uno de los determinantes del crecimiento económico. De acuerdo con las estimaciones de Rodrik (2007b) para los países en desarrollo entre 1950 y 2004, una subvaluación del tipo de cambio del $10 \%$ estuvo relacionada con un mayor crecimiento de $0,27 \%$ por año. Una de las explicaciones que ofrece el autor va en la línea de las externalidades que generan los sectores productores de bienes y servicios comercializables, e indica que la subvaluación del tipo de cambio opera como un sustituto parcial de una política de desarrollo productivo. Hausmann, Pritchet y Rodrik (2005) muestran, a su vez, que uno de los determinantes de las aceleraciones en los ritmos de crecimiento en los países en desarrollo es un tipo de cambio competitivo. Esta evidencia es, además, consistente con los resultados de Prasad, Rajan y Subramanian (2008) y la revisión de la literatura por 
parte de Frenkel y Rapetti (2010), de acuerdo con los cuales los mayores ritmos de crecimiento se relacionan con un mejor balance en cuenta corriente.

Frenkel y Taylor (2007) denominan este efecto del tipo de cambio real en el crecimiento como el "efecto sobre desarrollo" y lo diferencian de otros efectos de dicha variable: el macroeconómico de corto plazo, que es ambiguo según se ha visto, y el efecto en el empleo. Este efecto en el desarrollo está vinculado, en primer término, a las ya mencionadas externalidades que genera el desarrollo dinámico de los sectores productores de bienes y servicios comercializables, incluida su repercusión en la diversificación de la estructura exportadora. En segundo lugar, se relaciona con la menor sensibilidad de las economías con una cuenta corriente robusta a los giros bruscos de la cuenta de capitales, una de las lecciones más importantes de las crisis recientes, según se ha visto. Una forma de entender estos efectos es que un tipo de cambio competitivo y estable desplaza hacia arriba tanto la curva TT en el gráfico 6 (sustituye parcialmente a una política de desarrollo productivo), como la curva GG a la derecha (mejora el equilibrio macroeconómico).
Aparte de estos efectos en el desarrollo, el tipo de cambio tiene, como lo señalan Frenkel y Taylor (2007), repercusiones adicionales en el empleo, que se relacionan con su efecto en la elasticidad empleo-producto. Una revaluación real tiende a disminuir dicha elasticidad por dos vías diferentes: primero, porque propende a abaratar los equipos en economías que importan una proporción apreciable de ellos, lo que genera una sustitución de mano de obra por capital; segundo, porque tiende a sesgar la elección de insumos en los procesos productivos hacia insumos importados, lo que reduce los encadenamientos productivos internos.

La inestabilidad del tipo de cambio real incrementa, además, el riesgo y, por ende, aminora la inversión en la producción de bienes y servicios comercializables internacionalmente, tanto exportaciones como sustitutos de importación. Este problema se ve acrecentado por la mayor vulnerabilidad a choques de precios internacionales que caracteriza a los países dependientes en mayor medida de exportaciones de productos básicos. La mayor volatilidad del tipo de cambio real en los países de América del Sur, que se ilustra en el gráfico 7, se

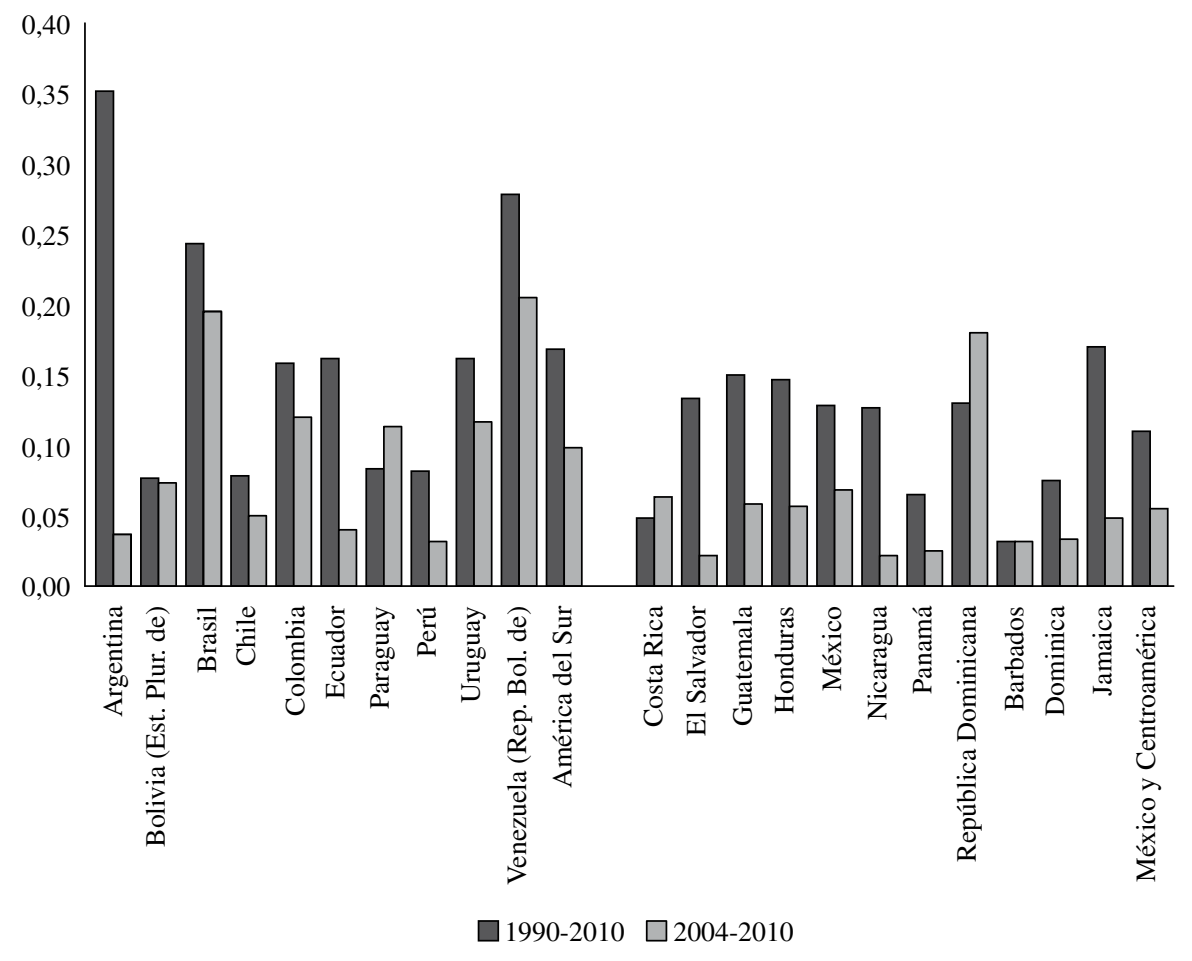

Fuente: estimaciones del autor sobre la base de datos de la Comisión Económica para América Latina y el Caribe (CEPAL). 
relaciona con la mayor dependencia de dichos productos por parte de esta subregión.

Este hecho resalta que los retos macroeconómicos son sobre todo importantes en economías cuya base exportadora tiene un componente relevante de bienes basados en recursos naturales y exige el desarrollo de mecanismos para hacer menguar la repercusión macroeconómica de las fluctuaciones de los precios de dichos bienes. Esto nos remite de nuevo a la importancia de los fondos de estabilización en estas economías.

En todo caso, conviene destacar que incluso en economías con una acentuada línea de exportaciones basadas en recursos naturales, el tipo de cambio real no está determinado exclusivamente por los precios

\section{V}

\section{Conclusiones}

En este trabajo se argumenta que la clave de una buena macroeconomía para el desarrollo es la combinación de acertadas políticas anticíclicas con una estrategia activa de diversificación productiva. La política fiscal anticíclica debe hacerse cargo de los retos que implican los agudos ciclos de financiamiento externo que enfrentan los países en desarrollo, pero también los vinculados al comercio internacional, especialmente las acentuadas fluctuaciones de los precios de productos básicos. La política fiscal anticíclica es un instrumento fundamental para ello, pero debe ir acompañada de una política monetaria y cambiaria igualmente anticíclica. El problema esencial en este último caso es moderar la presión hacia un manejo procíclico de la política monetaria y cambiaria que generan los ciclos de financiamiento externo en economías que han abierto su cuenta de capitales. A la luz de la experiencia del último decenio, ello parece posible con regímenes cambiarios intermedios que emplean el manejo activo de las reservas internacionales como mecanismo de estabilización, en conjunto con políticas macroprudenciales que incluyen regulaciones a los flujos de capital.

La necesidad de una estrategia de desarrollo productivo se sustenta en la estrecha relación que existe entre dinamismo económico y diversificación de las estructuras productivas. El centro de esa política es el fomento de actividades productivas innovadoras que generan fuertes encadenamientos productivos $\mathrm{y}$, a través de ello, competitividad sistémica. La innovación de los productos de exportación. En el gráfico 7 se aprecia, por ejemplo, que el Perú ha sido mucho más eficaz en evitar la volatilidad del tipo de cambio que otros países sudamericanos, como reflejo de la marcada intervención del banco central de ese país en los mercados cambiarios. La otra cara de la moneda es que la opción por tipos de cambio más flexibles tiene el efecto de aumentar la volatilidad del tipo de cambio real, especialmente en las economías dependientes de exportaciones basadas en recursos naturales. Esto favorece a regímenes de flexibilidad administrada del tipo de cambio, como parte de políticas anticíclicas de mayor alcance que se han analizado en secciones anteriores.

debe entenderse en un sentido amplio, no solo como innovación tecnológica, sino también como creación de nuevas actividades productivas, nuevas formas de comercialización, conquista de nuevos mercados, o nuevas formas de estructurar una empresa o una industria. Sin embargo, su prueba de fuego es la capacidad de acumular capacidades tecnológicas. El reto es sobre todo importante en economías que, como el grueso de las latinoamericanas, enfrentan ventajas comparativas estáticas ligadas a los recursos naturales. La explotación de tales ventajas no debe obstaculizar la diversificación de la estructura productiva y sí debe incorporar contenidos tecnológicos crecientes en las propias actividades vinculadas a los recursos naturales. El manejo apropiado del tipo de cambio a lo largo del ciclo económico es esencial para garantizar este resultado.

La política anticíclica y la diversificación productiva son medulares en los aportes de la CEPAL y, en particular, de don Raúl Prebisch, en cuyo honor se creó esta cátedra. En especial, se sustentan en dos conceptos fundamentales: el papel clave que tiene el manejo de las vulnerabilidades externas en economías sujetas a un "predominio de la balanza de pagos" en su dinámica macroeconómica, y la estrecha relación entre crecimiento económico y transformación productiva. Estas dos ideas centrales siguen siendo válidas tanto ayer como hoy y demuestran la validez de conceptos que ha defendido la CEPAL a lo largo de su historia. 
Agosin, Manuel (2007), "Trade and growth: why Asia grows faster than Latin America", Economic Growth with Equity: Challenges for Latin America, Ricardo Ffrench-Davis y José Luis Machinea (eds.), Houndmills, Palgrave/CEPAL.

Agosin, Manuel y Franklin Huaita (2009), "Overreaction in capital flows to emerging markets: booms and sudden stops", Documento de trabajo, $N^{\circ} 295$, Santiago de Chile, Departamento de Economía, Universidad de Chile.

Akyüz, Yilmaz (ed.) (2003), Developing Countries and World Trade: Performance and Prospects, Ginebra, Conferencia de las Naciones Unidas sobre Comercio y Desarrollo (UNCTAD).

Amsden, Alice (2001), The Rise of "The Rest": Challenges to the West from Late-Industrializing Economies, Nueva York, Oxford University Press, septiembre.

Bello, Omar y Juan Pablo Jiménez (2008), "Política fiscal y ciclo económico en América Latina", Santiago de Chile, Comisión Económica para América Latina y el Caribe (CEPAL).

Bértola, Luis y José Antonio Ocampo (2010), Desarrollo, vaivenes y desigualdad: una historia económica de América Latina desde la independencia, Madrid, Secretaría General Iberoamericana (SEGIB).

BID (Banco Interamericano de Desarrollo) (2008), All That Glitters May Not Be Gold: Assessing Latin America's Recent Macroeconomic Performance, Washington, D.C., abril.

Bielschowsky, Ricardo (1998), "Cincuenta años de pensamiento de la CEPAL", Cincuenta años de pensamiento de la CEPAL, Santiago de Chile, Fondo de Cultura Económica/CEPAL.

Blomström, Magnus y Ari Kokko (2007), "From natural resources to high-tech production: the evolution of industrial competitiveness in Sweden and Finland", Natural Resources: Neither Curse nor Destiny, Daniel Lederman y William F. Maloney (eds.), Washington, D.C., Banco Mundial.

Calvo, Guillermo, Leonardo Leiderman y Carmen Reinhart (1993), "Capital inflows and real exchange rate appreciation in Latin America: the role of external factors", IMF Staff Papers, $\mathrm{N}^{\circ} 40$, Washington, D.C., Fondo Monetario Internacional, marzo.

Calvo, Guillermo y Ernesto Talvi (2008), "Sudden stop, financial factors and economic collapse: a view from the Latin American frontlines", The Washington Consensus Reconsidered: Towards a New Global Governance, Narcis Serra y Joseph E. Stiglitz (eds.), Nueva York, Oxford University Press.

CEPAL (Comisión Económica para América Latina y el Caribe) (2010a), La hora de la igualdad: brechas por cerrar, caminos por abrir (LC/G.2432(SES.33/3)), Santiago de Chile.

(2010b), Panorama social de América Latina, Santiago de Chile.

(2008a), La transformación productiva 20 años después: viejos problemas, nuevas oportunidades (LC/G.2367(SES.32/3)), Santiago de Chile.

(2008b), Estudio económico de América Latina y el Caribe, 2007-2008 (LC/G.2386-P), Santiago de Chile. Publicación de las Naciones Unidas, $\mathrm{N}^{\mathrm{o}}$ de venta: S.08.II.G.2.

(2007), Progreso técnico y cambio estructural en América Latina (LC/W.136), Santiago de Chile, CEPAL/Centro Internacional de Investigaciones para el Desarrollo (IDRC, Canadá).

(2006), Panorama de la inserción internacional de América Latina y el Caribe, 2006-2007 (LC/G.2313-P), Santiago de Chile. Publicación de las Naciones Unidas, $\mathrm{N}^{\mathrm{o}}$ de venta: S.06. II.G.67.

(2000), Equidad, desarrollo y ciudadanía (LC/G.2071/ Rev.1-P), Bogotá, CEPAL/Alfaomega. Publicación de las Naciones Unidas, $\mathrm{N}^{\mathrm{o}}$ de venta: S.00.II.G.81.

(1998a), América Latina y el Caribe: políticas para mejorar la inserción en la economía mundial, Santiago de Chile, Fondo de Cultura Económica/CEPAL. (1998b), El pacto fiscal: fortalezas, debilidades, desafíos (LC/G.1997/Rev.1-P), Santiago de Chile. Publicación de las Naciones Unidas, $\mathrm{N}^{\circ}$ de venta: S.98.II.G.5.

(1998c), Estudio económico de América Latina y el Caribe, 1997-1998 (LC/G.2032-P), Santiago de Chile. Publicación de las Naciones Unidas, $\mathrm{N}^{\mathrm{o}}$ de venta: S.98.II.G.2.

(1990), Transformación productiva con equidad: la tarea prioritaria del desarrollo de América Latina y el Caribe en los años noventa (LC/G.1601-P), Santiago de Chile. Publicación de las Naciones Unidas, $\mathrm{N}^{\circ}$ de venta: S.90.II.G.6.

Cimoli, Mario y Gabriel Porcile (2011), "Learning, technological capabilities and structural dynamics", The Oxford Handbook of Latin American Economics, José Antonio Ocampo y Jaime Ros (eds.), Nueva York, Oxford University Press.

Cimoli, Mario, Giovanni Dosi y Joseph E. Stiglitz (2009), “The future of industrial policies in the new millennium: toward a knowledge-centered development agenda", The Political Economy of Capabilities Accumulation: the Past and Future of Policies for Industrial Development, Mario Cimoli, Giovanni Dosi y Joseph E. Stiglitz (eds.), Nueva York, Oxford University Press.

Devlin, Robert y Graciela Moguillansky (2010), Alianzas públicoprivadas para una nueva visión estratégica del desarrollo, serie Libros de la CEPAL, No 108 (LC/G.2426-P), Santiago de Chile, Comisión Económica para América Latina y el Caribe (CEPAL)/ Secretaría General Iberoamericana (SEGIB).

Díaz-Alejandro, Carlos F. (1988), Trade, Development and the World Economy: Selected Essays, Andrés Velasco (ed.), Oxford, Basil Blackwell.

Epstein, Gerald, Ilene Grabel y K.S. Jomo (2003), "Capital management techniques in developing countries", Challenges to the World Bank and the IMF: Developing Country Perspectives, Ariel Buira (ed.), Londres, Anthem Press.

Ffrench-Davis, Ricardo (2010), "Latin America: the structural fiscal balance policy in Chile: a move toward counter-cyclical macroeconomics", Journal of Globalization and Development, vol. 1, $\mathrm{N}^{\circ} 1$, Berkeley Electronic Press.

(2005), Reformas para América Latina: después del fundamentalismo neoliberal, Buenos Aires, Siglo XXI Editores Argentina.

(2001), Financial Crises in 'Successful' Emerging Economies, Washington, D.C., Brookings Institution Press.

Ffrench-Davis, Ricardo y Stephany Griffith-Jones (2011), "Taming capital account shocks: managing booms and busts", The Oxford Handbook of Latin American Economics, José Antonio Ocampo y Jaime Ros (eds.), Nueva York, Oxford University Press.

Ffrench-Davis, Ricardo, Oscar Muñoz y Gabriel Palma (1998), “The Latin American economies, 1959-1990", Latin America: Economy and Society Since 1930, Leslie Bethell (ed.), Cambridge, Cambridge University Press.

FMI (Fondo Monetario Internacional) (2010), Regional Economic Outlook, Western Hemisphere: Heating up in the South, Cooler in the North, Washington, D.C., octubre.

Frankel, Jeffrey y George Saravelos (2010), "Are leading indicators of financial crises useful for assessing country vulnerability? Evidence from the 2008-2009 global crisis", NBER Working Paper, $N^{\circ} 16047$, Cambridge, Massachusetts, National Bureau of Economic Research, junio.

Frenkel, Roberto (2010), "Lecciones de la política macroeconómica para el desarrollo a la luz de la experiencia de la última década", documento presentado en la XV reunión de investigadores de los bancos centrales del continente americano, organizada por el Centro de Estudios Monetarios Latinoamericanos (CEMLA) y el Banco Central de Bolivia ( 3 a 5 de noviembre).

(2008), "From the boom in capital inflows to financial traps", Capital Market Liberalization and Development, José 
Antonio Ocampo y Joseph E. Stiglitz (eds.), Nueva York, Oxford University Press.

(2007), "La sostenibilidad de la política de esterilización monetaria", Revista de la CEPAL, № 93 (LC/G.2347-P), Santiago de Chile, Comisión Económica para América Latina y el Caribe (CEPAL), diciembre.

Frenkel, Robert y Lance Taylor (2007), "Real exchange rate, monetary policies and employment", Policy Matters: Economic and Social Policies to Sustain Equitable Development, José Antonio Ocampo, Jomo K.S. y Sarbuland Khan (eds.), Hyderabad, Orient Longman.

Frenkel, Robert y Martin Rapetti (2010) "Economic development and the international financial system", Time for a Visible Hand: Lessons from the 2009 World Financial Crisis, Stephany GriffithJones, José Antonio Ocampo y Joseph E. Stiglitz (eds.), Nueva York, Oxford University Press.

Griffith-Jones, Stephany y José Antonio Ocampo (2010), "Building on the Counter-Cyclical Consensus: A Policy Agenda" [en línea] http://www.g24.org/research.htm

Hausmann, Ricardo (2011), "Structural transformation and economic growth in Latin America", The Oxford Handbook of Latin American Economics, José Antonio Ocampo y Jaime Ros (eds.), Nueva York, Oxford University Press.

Hausmann, Ricardo, Jason Hwang y Dani Rodrik (2007), "What you export matters", Journal of Economic Growth, vol. 12, № 1 , Berlin, Springer.

Hausmann, Ricardo, Lant Pritchet y Dani Rodrik (2005), "Growth accelerations", Journal of Economic Growth, vol. 10, No 4, Berlin, Springer.

Heymann, Daniel (2000), "Grandes perturbaciones macroeconómicas, expectativas y respuestas de política", Revista de la CEPAL, $\mathrm{N}^{\circ} 80$ (LC/G.2095-P), Santiago de Chile, Comisión Económica para América Latina y el Caribe (CEPAL), abril.

Hidalgo, C.A. y otros (2007), "The product space conditions the development of nations", Science, vol. 317, $\mathrm{N}^{\circ}$ 5837, Washington, D.C., American Association for the Advancement of Science, julio.

Hirschman, Albert O. (1958), The Strategy of Economic Development, New Haven, Yale University Press.

Kaminsky, Graciela L., Carmen M. Reinhart y Carlos A. Végh (2004), "When it rains, it tours: pro-cyclical capital flows and macroeconomic policies", NBER Working Paper, No 10780, Cambridge, Massachusetts, National Bureau of Economic Research.

Katz, Jorge (2000), Reformas estructurales, productividad y conducta tecnológica, Santiago de Chile, CEPAL/Fondo de Cultura Económica.

(1987), "Domestic technology generation in LDCs: a review of research findings", Technology Generation in Latin American Manufacturing Industries, Jorge Katz (ed.), Londres, Macmillan.

Kindleberger, Charles P. y Robert Aliber (2005), Manias, Panics, and Crashes: A History of Financial Crises, Nueva York, John Wiley and Sons.

Krugman, Paul (1987), "The narrow moving band, the Dutch disease and the competitive consequences of Mrs. Thatcher: notes on trade in the presence of scale dynamic economies", Journal of Development Economics, vol. 27, № 1-2, Amsterdam, Elsevier.

Krugman, Paul y Lance Taylor (1978), "Contractionary effects of devaluations", Journal of International Economics, vol. 8, № 3, Amsterdam, Elsevier.

Lederman, Daniel y William F. Maloney (2007), "Trade structure and growth", Natural Resources: Neither Curse nor Destiny, Daniel Lederman y William F. Maloney (eds.), Washington, D.C., Banco Mundial.

Llaudes, Ricardo, Ferhan Salman y Mali Chivakul (2010), "The impact of the great recession on emerging markets", IMF
Working Paper, $\mathrm{N}^{\mathrm{o}}$ 10/237, Washington, D.C., Fondo Monetario Internacional, octubre.

Manzano, Ozmel y Roberto Rigobón (2007), "Resource curse or debt overhang?", Natural Resources: Neither Curse nor Destiny, Daniel Lederman y William F. Maloney (eds.), Washington, D.C., Banco Mundial.

Marfán, Manuel (2005), "La eficacia de la política fiscal y los déficit privados: un enfoque macroeconómico", Más allá de las reformas: dinámica estructural y vulnerabilidad macroeconómica, José Antonio Ocampo (ed.), Bogotá, Alfaomega.

Martner, Ricardo y Varinia Tromben (2003), "Tax reforms and fiscal stabilization in Latin America", Tax Policy, Roma, Banco de Italia.

Minsky, Hyman P. (1982), Can “it” Happen Again?: Essays on Instability and Finance, Armonk, Nueva York, M.E. Sharpe.

Noyola, Juan (1956), "El desarrollo económico y la inflación en México y otros países latinoamericanos", Investigación económica, vol. 16, № 4, México, D.F., Universidad Nacional Autónoma de México.

Ocampo, José Antonio (2009), "Latin America and the global financial crisis”, Cambridge Journal of Economics, vol. 33, № 4, Oxford University Press, julio.

(2008), "A broad view of macroeconomic stability", The Washington Consensus Reconsidered, Narcis Serra y Joseph E. Stiglitz (eds.), Nueva York, Oxford University Press.

(2007), "La macroeconomía de la bonanza económica latinoamericana", Revista de la CEPAL, No 93 (LC/G.2347-P), Santiago de Chile, Comisión Económica para América Latina y el Caribe (CEPAL), diciembre.

(2005), "La búsqueda de la eficiencia dinámica: dinámica estructural y crecimiento económico en los países en desarrollo", Más allá de las reformas: dinámica estructural y vulnerabilidad macroeconómica, José Antonio Ocampo (ed.), Bogotá, Alfaomega.

(2004), "La América Latina y la economía mundial en el largo siglo XX”, El trimestre económico, vol. 71(4), № 284, México, D.F., Fondo de Cultura Económica, octubre-diciembre.

(2003), "Capital account and counter-cyclical prudential regulations in developing countries", From Capital Surges to Drought: Seeking Stability for Emerging Markets, Ricardo Ffrench-Davis y Stephany Griffith-Jones (eds.), Basingstoke, Palgrave.

Ocampo, José Antonio y Robert Vos (2008), Uneven Economic Development, Himayatnagar, Orient Longman.

Ocampo, José Antonio, Codrina Rada y Lance Taylor (2009), Growth and Policy in Developing Countries: A Structuralist Approach, Nueva York, Columbia University Press.

Ocampo, José Antonio y Mariángela Parra (2010), "The terms of trade for commodities since the mid-nineteenth century", Journal of Iberian and Latin American Economic History/Revista de historia económica, vol. 28, $\mathrm{N}^{\circ} 1$, Cambridge University Press, marzo.

Ocampo, José Antonio y otros (2010), "The Great Recession and the Developing World", documento preparado para la Presidencia Española de la Unión Europea, junio.

Olivera, J.H.G. (1964), "On structural inflation and Latin American structuralism", Oxford Economic Papers, vol. 16, № 3, Oxford, Oxford University Press, noviembre.

Ostry, Jonathan D. y otros (2010), "Capital inflows: the role of controls", Staff Position Note, No 2010/04, febrero [en línea] www.imf.org

Palma, José Gabriel (2011), "Why has productivity growth stagnated in most Latin American countries since the neo-liberal reforms?", The Oxford Handbook of Latin American Economics, José Antonio Ocampo y Jaime Ros (eds.), Nueva York, Oxford University Press.

(2009), "Flying geese and waddling ducks: the different capabilities of East Asia and Latin America to 'demand-adapt' 
and 'supply-upgrade' their export productive capacity", The Political Economy of Capabilities Accumulation: the Past and Future of Policies for Industrial Development, Mario Cimoli, Giovanni Dosi y Joseph E. Stiglitz (eds.), Nueva York, Oxford University Press.

Prasad, Eswar S., Raghuram R. Rajan y Arvind Subramanian (2008), "Foreign capital and economic development", Brookings Papers on Economic Activity, $\mathrm{N}^{\mathrm{o}}$ 1, Washington, D.C., The Brookings Institution.

Prebisch, Raúl (1973), Interpretación del proceso de desarrollo latinoamericano en 1949, serie conmemorativa del XXV aniversario de la CEPAL, Santiago de Chile, Comisión Económica para América Latina y el Caribe (CEPAL).

Reinhart, Carmen y Kenneth Rogoff (2009), This Time is Different: Eight Centuries of Financial Folly, Princeton, Princeton University Press.

Rodríguez, Octavio (2006), El estructuralismo latinoamericano, México, D.F., Siglo XXI Editores/CEPAL.

Rodrik, Dani (2007a), One Economics, Many Recipes: Globalization, Institutions and Economic Growth, Princeton, Princeton University Press.

(2007b), The Exchange Rate and Economic Growth: Theory and Evidence, Cambridge, Harvard University, John F. Kennedy School of Government, julio.

Rodrik, Dani y Andrés Velasco (2000), "Short-term capital flows", Proceedings of the Annual World Bank Conference on Development Economics 1999, Washington, D.C., Banco Mundial.

Ros, Jaime (2000), Development Theory and the Economics of Growth, Ann Arbor, University of Michigan Press.

Rosenthal, Gert (2004), "ECLAC: a commitment to a Latin American way towards development", Unity and Diversity in Development
Ideas: Perspectives from the UN Regional Commissions, Yves Berthelot (ed.), Bloomington, Indiana University Press.

Sachs, Jeffrey y Andrew Warner (1995), "Economic reform and the process of global integration", Brookings Papers on Economic Activity, vol. 26, $\mathrm{N}^{\circ}$ 1, Washington, D.C., The Brookings Institution

Saurina, Jesús (2009), "Dynamic provisioning, the experience of Spain", Policy for the Private Sector, Note, $\mathrm{N}^{\mathrm{o}}$ 7, Washington, D.C., Banco Mundial, julio.

Stiglitz, Joseph E. (1998), "More Instruments and Broader Goals: Moving toward the Post-Washington Consensus" [en línea] http://www.wider.unu.edu/events/annual-lecture/Past-annuallectures/en_GB/1998/

Stiglitz, Joseph E. y Amar Bhattacharya (2000), "The underpinnings of a stable and equitable global financial system: from old debates to a new paradigm", Proceedings of the Annual World Bank Conference on Development Economics 1999, Washington, D.C., Banco Mundial.

Stiglitz, Joseph E. y otros (2006), Stability with Growth: Macroeconomics, Liberalization, and Development, Nueva York, Oxford University Press.

Sunkel, Osvaldo (1958), "La inflación chilena: un enfoque heterodoxo", El trimestre económico, vol. 25, No 4, México, D.F., Fondo de Cultura Económica, octubre-diciembre.

Svensson, Lars E.O. (2000), "Open-economy inflation targeting”, Journal of International Economics, vol. 50, № 1, Amsterdam, Elsevier.

Taylor, Lance (1991), Income Distribution, Inflation and Growth, Cambridge, Massachusetts, The MIT Press.

Vos, Robert y otros (2006), Who Gains from Free Trade? Export-led Growth, Inequality and Poverty in Latin America, Londres, Routledge. 